\title{
Gata3 Is a Critical Regulator of Cochlear Wiring
}

\author{
Jessica M. Appler, ${ }^{\star}$ Cindy C. Lu, ${ }^{\star}$ Noah R. Druckenbrod, Wei-Ming Yu, Edmund J. Koundakjian, and Lisa V. Goodrich \\ Department of Neurobiology, Harvard Medical School, Boston, Massachusetts 02115
}

Spiral ganglion neurons (SGNs) play a key role in hearing by rapidly and faithfully transmitting signals from the cochlea to the brain. Identification of the transcriptional networks that ensure the proper specification and wiring of SGNs during development will lay the foundation for efforts to rewire a damaged cochlea. Here, we show that the transcription factor Gata3, which is expressed in SGNs throughout their development, is essential for formation of the intricately patterned connections in the cochlea. We generated conditional knock-out mice in which Gata3 is deleted after SGNs are specified. Cochlear wiring is severely disrupted in these animals, with premature extension of neurites that follow highly abnormal trajectories toward their targets, as shown using in vitro neurite outgrowth assays together with time-lapse imaging of whole embryonic cochleae. Expression profiling of mutant neurons revealed a broad shift in gene expression toward a more differentiated state, concomitant with minor changes in SGN identity. Thus, Gata3 appears to serve as an "intermediate regulator" that guides SGNs through differentiation and preserves the auditory fate. As the first auditory-specific regulator of SGN development, Gata3 provides a useful molecular entry point for efforts to engineer SGNs for the restoration of hearing.

\section{Introduction}

The perception of sound is mediated by precisely wired circuits in the inner ear (Appler and Goodrich, 2011). Sound stimuli are detected by hair cells in the cochlea and transmitted to the CNS by spiral ganglion neurons (SGNs). SGNs play a central role in auditory perception, because they must faithfully encode and communicate the frequency, duration, and intensity of all sounds to the CNS. For instance, hair cells and SGNs are arranged from low to high sound frequencies along the apical-basal axis, with each SGN innervating a single inner hair cell. This strict tonotopic organization is preserved in the central SGN projections, which exit through the eighth nerve and terminate in the cochlear nucleus, with low-frequency neurons projecting more ventrally than high-frequency neurons. Hence, the intricate wiring of the cochlea is a physical representation of the logic underlying sound perception.

Deciphering the developmental mechanisms that establish cochlear wiring is fundamental for efforts to treat deafness. Hearing loss is a common sensory disorder in humans, ranging from

Received Oct. 4, 2012; revised Dec. 18, 2012; accepted Jan. 2, 2013.

Author contributions: J.M.A., C.C.L., E.J.K., and L.V.G. designed research; J.M.A., C.C.L., N.R.D., W.-M.Y., and E.J.K. performed research; J.M.A., C.C.L., N.R.D., and L.V.G. analyzed data; C.C.L. and L.V.G. wrote the paper.

*J.M.A. and C.C.L. contributed equally to this work.

This work was funded by National Institute on Deafness and Other Communication Disorders Grants R01 DC009223 (L.V.G.), R21 DC011122 (L.V.G.), F31 DC007775 (E.J.K.), and F32 DC008228 (C.C.L.), National Institute of Neurological Disorders and Stroke Grant T32 NS007484 (N.R.D.), the Mathers Charitable Foundation (L.V.G.), a Kaneb Fellowship (L.V.G.), a Lefler Research grant (L.V.G.), the Quan Family (J.M.A. and E.J.K.), and the Brooks Foundation (W.-M.Y.). We thank the following: D. Corey and members of his laboratory for sharing equipment and especially for use of the confocal microscope; M. Gordon for genotyping assistance; S. Ross, J. Johnson, I. Ho, L. Glimcher, and H. van Doorninck for providing animals; S. Darin and D. Harmin for help with the statistics; the Harvard NeuroDiscovery Center optical imaging facility; T. Coate and M. Kelley for advice on dissections of early cochleae; B. Fritzsch for frequent advice and input into the project; and B. Datta for helpful comments on this manuscript.

The authors declare no competing financial interests.

Correspondence should be addressed to Lisa V. Goodrich, Department of Neurobiology, Harvard Medical School, Goldenson 4th Floor, 220 Longwood Avenue, Boston, MA 02115. E-mail: Lisa_Goodrich@hms.harvard.edu.

DOI:10.1523/JNEUROSCI.4703-12.2013

Copyright $\odot 2013$ the authors $\quad 0270-6474 / 13 / 333679-13 \$ 15.00 / 0$ inherited deafness at birth to adult-onset hearing loss attributable to noise, trauma, or aging (Friedman et al., 2007; Konings et al., 2009; Bielefeld et al., 2010). Although the causes of deafness are diverse, cochlear implants offer a broadly effective treatment, because they circumvent abnormal cochlear function by directly stimulating the cochlear nerve. An exciting possible treatment for deafness is to stimulate hair cell regeneration (Okano and Kelley, 2012). Importantly, both approaches require the presence of SGNs that maintain proper connections with the cochlea and the brain. Although SGNs are an important therapeutic target, we do not yet have a molecular entry point for creating SGNs or controlling their connectivity. Identification of the intrinsic factors that govern auditory-specific features of SGN development would provide an important step forward.

Developing SGNs experience a complex series of generic and cell-type-specific changes in gene expression that unfold over time (Lu et al., 2011). In other systems, programs of gene expression are activated by combinatorial codes of transcription factors that determine the fate of a particular neuron. Subsequently, neurons undergo dramatic changes in gene expression that allow their projections to find their way to the appropriate targets and form synapses. Unfortunately, little is known about how these complex events are broadly orchestrated. Clues from the immune system support the need for additional transcriptional control as differentiation progresses. For instance, ongoing regulation of T-cell identity at intermediate stages is necessary to repress nonT-cell genes and activate pro-T-cell pathways (David-Fung et al., 2006). Moreover, transitions through each stage remain flexible, such that $\mathrm{T}$ cells can adapt in response to cues in their environment. Hence, cell identities emerge gradually, with multiple differentiation events coordinated in parallel.

Here, we sought to identify intrinsic regulators of SGN development. We found that the zinc finger transcription factor Gata3 plays a key role by coordinating both the maintenance and execution of SGN cell fates, as well as the formation of their stereotyped patterns of connections in the cochlea. 


\section{Materials and Methods}

Mice. The following mouse strains were used and PCR genotyped as described previously: two floxed alleles: Gata $3^{f l}$ (Zhu et al., 2004) and Gata3 $^{\text {Ho }}$ (Pai et al., 2003), a null tauLacZ knock-in allele of Gata3 $\left(\right.$ Gata3 $^{-}$) (van Doorninck et al., 1999), Bhlhb5-Cre (Ross et al., 2010), Neurog1-Cre (Quinoñes et al., 2010), the placental alkaline phosphatase (PLAP) reporter (Z/AP) (Lobe et al., 1999), the GFP reporter (Z/EG) (Novak et al., 2000), and the tdTomato reporter [Gt(Rosa)26Sortm14 (CAG-tdTomato)Hze] (Allen Brain Science Institute). Mice were also genotyped by 5 -bromo-4-chloro-3-indolyl- $\beta$-D-galactopyranoside (X-gal) staining or PLAP staining of tissue and by monitoring for the presence of fluorescence in the presence of Cre. For embryonic collections, noon on the day of the plug was considered embryonic day 0.5 (E0.5). For postnatal collections, the day of birth was called P0. Embryos and pups of either sex were used. Animals were maintained and handled according to protocols approved by the Institutional Animal Care and Use Committee at Harvard Medical School.

Alkaline phosphatase and LacZ staining. Detection of alkaline phosphatase and $\beta$-galactosidase was performed as described previously (Koundakjian et al., 2007; Abraira et al., 2008).

Antibody staining. For Gata3 antibody staining, tissue was fixed in $4 \%$ paraformaldehyde (PFA) in $0.067 \mathrm{M}$ Sorenson's buffer overnight at $4^{\circ} \mathrm{C}$. E9.5 tissue was embedded in 4\% low-melting-point agarose in PBS and cut into $50 \mu \mathrm{m}$ sections using a vibratome. For later stages, tissue was stepped through 10, 20, and 30\% sucrose in 0.067 M Sorenson's buffer, frozen in Neg50, and cryosectioned at $14 \mu \mathrm{m}$. Tissue was treated with $0.005 \%$ trypsin in $0.1 \mathrm{M} \mathrm{CaCl}_{2}, \mathrm{pH} 7.4$, for $5 \mathrm{~min}$, rinsed in PBS, and blocked in 5\% normal donkey serum and $0.5 \%$ Triton X-100 for $1 \mathrm{~h}$ at room temperature. Sections were then incubated in goat anti-Gata3 (1: 100 , AF2605; R\&D Systems) in 5\% normal donkey serum in PBS overnight at $4^{\circ} \mathrm{C}$. Alexa Fluor-conjugated secondary antibodies (Invitrogen) were used for signal detection.

For whole-mount neurofilament (NF) and Myosin 6 (Myo6) staining, E15.5 embryo heads were fixed in 4\% PFA overnight, and cochleae were dissected and blocked in PBS with 1\% Triton X-100 and 5\% normal donkey serum for $2 \mathrm{~h}$ at room temperature. Cochleae were then incubated in rabbit anti-Myo6A (1:150; Proteus BioSciences) and chicken anti-NF-H (1:2000; Millipore Bioscience) primary antibodies overnight at $4^{\circ} \mathrm{C}$, followed by Alexa Fluor-568 donkey anti-rabbit (1:1000) and Alexa Fluor-488 donkey anti-chicken (1:1000) for $2 \mathrm{~h}$ at room temperature. For $\mathrm{Hu}$ and Myo6 staining, tissue was blocked in 5\% goat serum, $1 \%$ Triton $\mathrm{X}-100$, and $0.05 \%$ sodium azide in PBS for $2 \mathrm{~h}$ and then incubated in antibody overnight at $4^{\circ} \mathrm{C}$ in $0.3 \%$ Triton $\mathrm{X}-100$ and $0.05 \%$ sodium azide in PBS. Human anti-Hu (1:1000) (Fairman et al., 1995) and rabbit anti-Myo6 (1:1000; Proteus Biosciences) were used as primary antibodies, and Alexa Fluor-conjugated secondary antibodies were used for signal detection. Whole-mount staining of E12.5 cochleae was performed similarly, using a rabbit anti-TuJ antibody (1:1000; Covance). Measurement of E12.5 neurite density was performed on maximum projected $z$-stacks with 10-20 $\mu \mathrm{m}$ steps taken through the entire region of interest. A binary mask was created within the measurement area, and an invariable threshold setting was applied for calculation of square micrometers for all preparations.

For whole-mount E14.5 and E15.5 cleaved-caspase 3 staining, embryo heads were fixed for $2 \mathrm{~h}$ at room temperature, permeabilized for $30 \mathrm{~min}$ in PBS with $0.5 \%$ Triton X-100, 1\% BSA, and 5\% normal donkey serum, and then incubated in primary and secondary antibodies sequentially overnight, rotating gently at $4^{\circ} \mathrm{C}$ in PBS with $0.1 \%$ Tween, $1 \%$ BSA, and $5 \%$ normal donkey serum. Rabbit anti-cleaved caspase 3 antibody (1: 100; Cell Signaling Technology) and mouse anti-TuJ (1:500; Covance) were used as the primary antibodies, and Alexa Fluor-conjugated secondary antibodies were used for signal detection. For quantification, cochleae were flat mounted blind to genotype, and caspase-positive cells were counted in multiple focal planes through the spiral ganglia at $20 \times$ magnification. Each cochlea was examined base to apex, and only cells contained within the spiral ganglion (as defined by TuJ-positive cell staining) were counted. For E14.5, cochleae from three control and three mutant embryos were scored. For E15.5, cochlea from five control and four mutant embryos were scored.

Tonotopic dye labeling. E15.5 embryo heads were fixed in 4\% PFA in PBS overnight and rinsed in PBS and then bisected midsagittally, and the cochlea was exposed so that basal and apical turns were visible. A small crystal of DiI was placed in the base of the cochlea, and a crystal of DiD was placed in the apex. Tissue was incubated at $37^{\circ} \mathrm{C}$ in PBS for $4-5 \mathrm{~d}$ to allow dye to travel through axons. The cochlear nucleus was then dissected out and cleared in ScaleA2 (Hama et al., 2001) at $37^{\circ} \mathrm{C}$ for $1 \mathrm{~h}$. Tissue was mounted on a slide and imaged by confocal microscopy.

Microarrays. Spiral ganglia were collected from E13.5 embryos that were either Bhlhb5-Cre;Gata $3^{\mathrm{Ho} /+}$ (control) or Bhlhb5-Cre;Gata $3^{\mathrm{Ho} /-}$ (mutant). For these experiments, we used the floxed $\mathrm{Gata}^{\mathrm{Ho}}$ allele (Pai et al., 2003), which expresses GFP during recombination of the Gata3 locus. Cre-positive embryos were identified by GFP signal, and the Gata $^{\text {tlz }}\left(\right.$ Gata3 $\left.^{-}\right)$was identified by $\beta$-galactosidase activity in tails. Ganglia were collected as described previously (Lu et al., 2011) and were pooled by genotype, with 18 ganglia (approximately nine animals) per sample and three samples for each genotype. Purification of RNA, generation of cDNA, and hybridization to Affymetrix Mouse Expression Array 4302.0 chips was performed and normalized as described previously (Lu et al., 2011), with the baseline array set as littermate control Bhlhb5-Cre;Gata $3^{\mathrm{Ho} /+}$ sample \#1 $(505,52.8 \%)$. The data were filtered down to 24,020 probe sets by requiring the $\mathrm{P}$ call percentage to be $>50 \%$. For analysis of differentially expressed genes, we used SAM (Significance Analysis of Microarrays) version 4.0 (http://www-stat.stanford. $\mathrm{edu} / \sim \mathrm{tibs} / \mathrm{SAM} /$ ) to compare Bhlhb5-Cre;Gata $3^{\mathrm{Ho} /-}$ to control Bhlhb5Cre; $\mathrm{Gata}^{\mathrm{Ho} /+}$ data. We set a 1.2 -fold change minimum and a false discovery rate of $10 \%$ (delta value 0.85 ). For gene ontology analysis, we used DAVID (http://david.abcc.ncifcrf.gov/).

Genes were categorized based on their wild-type spatial [enriched in SGNs ("SG") or vestibular ganglion neurons (VGNs) ("VG") by at least 1.5 -fold] and temporal [ $>1.5$-fold enriched at E12 or E13 vs later stages ("early") or at E16 to P15 compared with early stages ("mid/late")] expression patterns. A handful of genes showed enriched expression in SGNs at all stages and were defined as "SG markers"; "VG markers" were similarly defined. Some genes ("unclassified") could not be easily categorized because of their complex spatiotemporal expression.

In situ hybridization. In situ hybridization was performed essentially as described previously (Abraira et al., 2008), except that fluorescence detection was used. Tissue was incubated in 1:500 anti-DIG POD Fab fragment (Roche Applied Science) overnight at $4^{\circ} \mathrm{C}$, washed three times for 5 min in TNT buffer $(0.05 \%$ Tween 20 in $100 \mathrm{~mm}$ Tris HCl, pH7.5, and 150 mu NaCl), detected using 1:100 Cy3 Tyr (PerkinElmer Life and Analytical Sciences) in amplification diluent for $10 \mathrm{~min}$, and then coverslipped in Vectashield (Vector Laboratories).

Quantitative RT-PCR. E13.5 spiral ganglia from Gata3 ${ }^{f l /+}$ (wild type, $n=4)$ or Bhlhb5-Cre;Gata $3^{f / /-}$ (mutant, $n=8$ ) were collected as described for microarrays and pooled, and total RNA was isolated using the RNeasy mini kit (Qiagen). cDNA was amplified using random primers and Superscript III (Invitrogen).

For RT-PCR, the following primers were used: Ntng1, TTCGTGTGGGGACATTATGA and GGGTACTCGCATCACACTCA; Chrdnll, ACCTGTGCATTCCCAGTCTC and TCCAGCTTGTCTGTTTGGTG.

Standard curves were generated for each primer set using 500, 100, 10, and $1 \mathrm{ng}$ of cDNA from E13 SG and VG and P0 cochlea as template. In all cases, amplification was linear $\left(R^{2}>0.99\right)$. SYBR Green-based detection was used (Applied Biosystems), and reactions were performed in triplicate. Fold-difference was calculated using the $\Delta \Delta C(t)$ method, with normalization against Gapdh. Primers used for quantitative PCR (qPCR) were as follows: Hook1, AAGCTTGACCAGTTGGATGG and AGGCTCGTCAGCTCATCATT; Lmnb1, CAGGAATTGGAGGACATGCT and GAAGGGCTTGGAGAGAGCTT; Phip, TTGGTTTTGGGTCCAGTAGC and AACCAATCGCTGGTACCTT; Rgs7bp, AACCAAAGGCTGTGAAATGG and ACTGAAGAGACCCCAGCAGA; Sparcl1, GACTGG CGAGAGTGAGAACC and AGGGGGACAAGTCTCTGGAT; Coch, GTGATGCCATCGCCTTTACT and GCGTGTGACTCTTTGGGTTT; Onecut1, CCCTGGAGCAAACTCAAGTC and TGGACGTCTGTGAAG ACCAG; $P c d h 19$, CAAGGACCTAGAGGGCAACA and TCTTCCCTG 
CAATGAAATCC;Gata3,TACCACCTATCCGCCCTATGandGCAGGC ATTGCAAAGGTAGT; and Gapdh, CATGGCCTTCCGTGTTCCTA and CCTGCTTCACCACCTTCTTGAT.

Neurite outgrowth assay. E12.5 and E13.5 spiral ganglia were isolated by dissection in PBS with $50 \mathrm{~mm}$ glucose, transferred into a drop of ice-cold 75\% Matrigel $/ 25 \%$ rat tail collagen in a 24 -well dish, and then allowed to set at $37^{\circ} \mathrm{C}$ for $5 \mathrm{~min}$. Explants were cultured in $50 \% \mathrm{~F}-12,40 \%$ OptiMEM, 5\% horse serum, $40 \mathrm{~mm}$ glucose, $2 \%$ GlutaMAX, and $1 \mathrm{ng} / \mu \mathrm{l}$ each BDNF, NT-3, and CNTF for $4 \mathrm{~d}$ at $37^{\circ} \mathrm{C}$ in a $5 \% \mathrm{CO}_{2}$ cell culture incubator, fixed in $4 \%$ PFA in PBS for $1 \mathrm{~h}$ at room temperature, and stained with a rabbit anti-TuJ antibody (Covance) as described above. The neurite outgrowth index (NOI) for mutant $(n=18)$, and Gata $3^{\mathrm{Ho} /+}$ $(n=19)$, Gata3 $^{\mathrm{Ho} /-}(n=12)$, and Bhlhb5-Cre;Gata $3^{\mathrm{Ho} /+}(n=30)$ control animals was quantified by measuring the relative area of neurite outgrowth, normalized to variations in the size of the region containing the cell bodies: NOI $=(E-C) / C$, where NOI is the outgrowth index, $E$ is the explant area, and $C$ is the cell body area. Statistical significance was assessed using the Kolmogorov-Smirnov (KS) test to compare distributions.

Live imaging and analyses. To prepare the imaging dish, black paper (0.45 $\mu \mathrm{m}$, black gridded, type HABG; Millipore) was cut into $4 \mathrm{~mm}$ squares and sterilized in $70 \%$ ethanol. Holes were cut in the middle of each square with a tungsten needle, and the square was affixed into a 35 $\mathrm{mm}$ glass-bottom dish (MatTek) with silicone grease (Dow Corning), and washed with serum-free culture media three times at $37^{\circ} \mathrm{C}$. E14.5 Bhlhb5-Cre;tdTomato;Gata $3^{\mathrm{Hol}+}$ (heterozygous) or Bhlhb5-Cre;tdTomato; Gata $3^{\mathrm{Ho} /-}$ (mutant) embryos were isolated and checked for fluorescence and LacZ activity. Before the availability of the $t d$ Tomato allele, the $Z / E G$ allele was used; similar results were seen using both reporters. The cochleae were dissected and rinsed in Hanks' buffered solution with $20 \mathrm{mM}$ HEPES (HHBS) and then placed above the center of the paper hole at the bottom of the imaging dish. The edges of extracochlear tissue were attached to the paper with light pressure applied by tungsten needles. Amnion membrane collected from the same litter was washed in HHBS, stretched across the cochlea, and attached to the paper to further secure the tissue. The HHBS was removed and replaced with culture medium [modified DF-12 with $28 \mathrm{~mm}$ dextrose (Sigma), $9 \mathrm{~mm}$ sodium bicarbonate (Sigma), 15 mм HEPES (Invitrogen), 2 mм GlutaMAX (Invitrogen), and $10 \%$ fetal calf serum (Invitrogen)], and the dish was placed in a $37^{\circ} \mathrm{C}$ incubator for $30 \mathrm{~min}$, after which prewarmed culture media was added to surface tension. The dish was then sealed with a silicone-grease covered lid, inverted, and punctured with a flamed 20 gauge needle for thermistor access. The dish was placed in a fitted heating chamber (Harvard Apparatus) and connected to a thermostat set to hold the temperature at $37^{\circ} \mathrm{C}$. Confocal images were taken at the cochlea base with a $40 \times$ or $60 \times$ objective every $10-24 \mathrm{~min}$, at six to nine focal planes separated by $10-20 \mu \mathrm{m}$, using Fluoview acquisition software (Olympus).

Fluoview time-lapse files were processed and analyzed with NIH ImageJ and MetaMorph software. Each Fluoview file was converted with custom macros into red-green-blue-depth coded movies. Briefly, each time point stack was divided by three, assigned a color, and then projected by maximum pixel intensity. The resultant red green and blue images were then overlaid. SGN processes were manually tracked and defined as any and all protrusions $50 \mu \mathrm{m}$ peripheral from the ganglion that could be delineated from its neighbors and could be tracked for more than four time intervals. The $x y$ coordinates for all tracks were recorded and plotted to show their orientation and start/stop points using Prism (GraphPad Software). Tracks were superimposed on a similar origin using Photoshop (Adobe Systems).

Quantification of reversals was performed for each trajectory by counting the number of intervals with a backward vector component, with forward being toward the organ of Corti. Statistical significance was assessed based on negative binomial generalized estimating equation (GEE) estimates. For quantification of tangential trajectories, a vector was drawn from the start to the end point of each track, and the angle of this vector relative to a radial vector was determined. All trajectories with $>30^{\circ}$ deviation from radial were scored as tangential. Measurement of neurite density was performed on maximum projected $z$-stacks with $10-20 \mu \mathrm{m}$ steps taken through the entire region of interest. Measure- ment of signal intensity over time was done by averaging pixel intensity within a specified region. These values were normalized to their maximum value and plotted using Excel (Microsoft). To quantify density at the end of the experiment, the tissue was fixed and imaged using a confocal microscope. A binary mask was created within the measurement area, and an invariable threshold setting was applied for calculation of square micrometers for all preparations.

\section{Results}

Gata3 is maintained in SGNs throughout circuit assembly

Previously, we documented the molecular and cellular changes in gene expression that occur in SGNs throughout auditory circuit assembly (Koundakjian et al., 2007; Lu et al., 2011). We hypothesized that proper deployment of these events over time must depend on the activity of transcriptional regulators that guide SGNs through intermediate stages of differentiation. An excellent candidate for such a role is the transcription factor Gata3, the earliest known indicator of SGN fate (Lawoko-Kerali et al., 2004). Notably, Gata3 continues to be transcribed in SGNs at least through birth (Rivolta and Holley, 1998; Lilleväli et al., 2004; Lu et al., 2011), raising the possibility that Gata3 acts during later stages of cochlear wiring.

To gain additional evidence for a possible role controlling gene expression in differentiating SGNs, we sought to confirm nuclear expression of Gata3 protein during important stages of auditory circuit assembly. In the mouse, SGNs are specified early during inner ear development (Lawoko-Kerali et al., 2004), with neurons delaminating from the otic vesicle between E9.5 and E12.5 (Carney and Silver, 1983; Ma et al., 1998; Koundakjian et al., 2007). SGNs then become bipolar and extend neurites through the mesenchyme toward the nascent organ of Corti, forming a meshwork of processes by E14.5 (Fig. $1 A, B$ ). Between E14.5 and E15.5, the processes undergo a dramatic transformation, growing longer and straighter and coalescing to form the radial bundles (Fig. 1C) (Coate et al., 2012) that characterize the mature wiring pattern of the cochlea (Fig. 1D). At each of these distinct stages, we found that Gata3 protein was localized to the nucleus, with abundant expression in SGNs at E14.5 (Fig. 1E), E15.5 (Fig. $1 F$ ), and P0 (Fig. $1 G$ ). Hence, Gata3 may continue to influence SGN development after their initial specification.

\section{Maintained Gata3 expression is required for proper peripheral wiring of SGNs}

The maintained expression of Gata3 suggests an ongoing role during intermediate stages of SGN differentiation. In support of this idea, Gata3 is required for multiple stages of T-cell development, from specification to differentiation and survival (Ho et al., 2009). Several studies of Gata3 in the inner ear hinted at a role in SGN specification at early otic vesicle stages (Karis et al., 2001; Lilleväli et al., 2006; Haugas et al., 2012). In support of this idea, constitutive Gata3 mutant cochleae are devoid of SGNs; only the closely related vestibular ganglion neurons (VGNs) remain (Duncan et al., 2011). However, Gata3 is broadly expressed in the otic vesicle, including cells in the organ of Corti (Figs. 1,2) and is also required for canal morphogenesis and sensory development (Rivolta and Holley, 1998; Karis et al., 2001; Lawoko-Kerali et al., 2004; Lilleväli et al., 2004, 2006; Duncan et al., 2011; Haugas et al., 2012). The severity of the inner ear phenotype has therefore precluded analysis of possible later roles for Gata3 in SGN development.

To circumvent the pleiotropic effects of Gata3, we used a Bhlhb5-Cre driver to delete Gata3 from SGNs without affecting expression elsewhere in the inner ear. SGNs are specified while they are still within the proneurosensory domain of the otic ves- 
icle and then delaminate away to form a cochlear-vestibular ganglion (Alsina et al., 2004; Appler and Goodrich, 2011). After proliferation ceases, SGNs begin to differentiate, as evidenced by extension of neurites back toward the otic vesicle, with most cells born by E11.5 and clear evidence of neurite extension by E12.5 (Matei et al., 2005; Koundakjian et al., 2007). Analysis of Bhlhb5-Cre activity confirmed recombination only in postdelamination neurons as early as E9.5, with no expression in the Gata3-positive cells still in the otic vesicle (Fig. $2 A, B$ ). Indeed, Bhlhb5-Cre;Gata $3^{f l /-}$ mutants (referred to as $\mathrm{Gata}^{\mathrm{CKO}}$ ) showed a severe reduction in Gata3 levels in SGNs at E13.5, whereas expression was maintained in the rest of the cochlea (Fig. $2 C, D)$. Although the Bhlhb5-Cre allele also drives expression in efferent neurons that innervate the cochlea, a similar phenotype was observed using an Neurog1Cre line, which drives recombination only in SGNs and not in efferent neurons (data not shown), indicating that the phenotype reflects an SGN-autonomous function for Gata3. Together, these studies confirm that we have successfully attenuated Gata3 activity in SGNs after specification.

Because a key feature of SGN differentiation is the formation of orderly connections with hair cells, we examined the wiring pattern of Gata3 ${ }^{C K O}$ cochleae at E15.5, when radial bundles are first apparent. Unlike Gata3 null mutants (Karis et al., 2001; Lilleväli et al., 2006; Duncan et al., 2011; Haugas et al., 2012), Gata3 ${ }^{\text {CKO }}$ cochleae were normal in size and shape and clearly formed a spiral ganglion. However, cochlear wiring was dramatically disrupted in these animals, as evidenced by the failure of peripheral projections to coalesce into organized bundles (Fig. 2E, F). Instead, they formed a dense, disorganized mesh extending from the ganglion to the sensory epithelium. Individual processes exhibited tortuous paths through the mesenchyme but nevertheless reached the nascent inner hair cells (Fig. 2G,H). Hence, maintained Gata3 is essential for normal cochlear wiring in vivo.

To gain a more complete understanding of how loss of Gata3 affects SGN differentiation after the axon outgrowth and pathfinding stage, we examined Gata3 ${ }^{C K O}$ cochleae at E16.5 and P0. The reticulated pattern of processes seen in Gata ${ }^{C K O}$ mutants at E15.5 persisted at E16.5 (Fig. $3 B$ ), with no evidence of the radial bundles seen in controls (Fig. $3 A$ ). In addition, there appeared to be fewer neurons. Loss of SGNs was even more prominent by P0, with a striking decrease in the number of peripheral projections in mutants compared with controls (Fig. $3 C, D$ ). To quantify this effect and determine its onset, we performed caspase antibody staining to label apoptotic cells. Although no difference in the
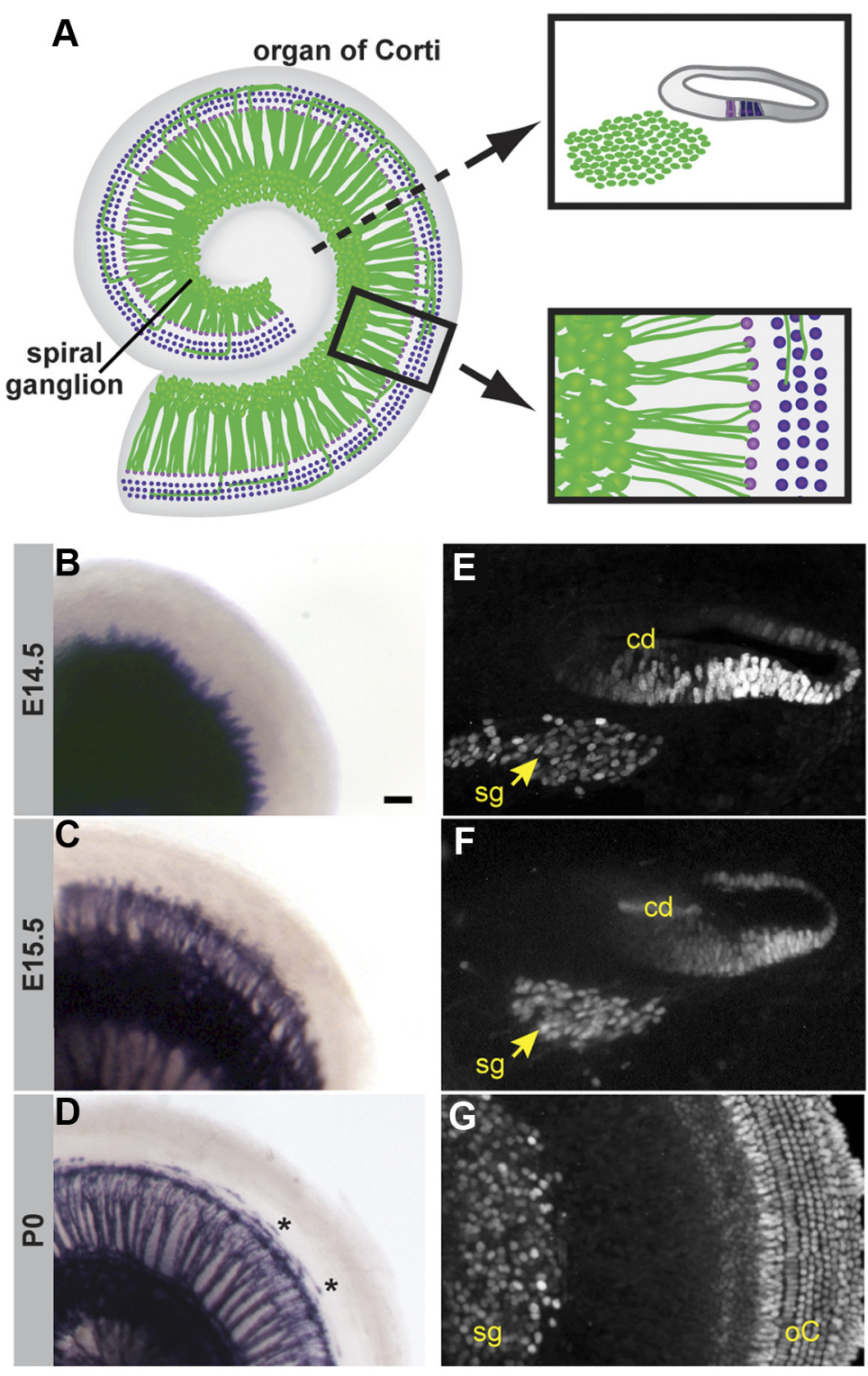

Figure 1. Gata3 expression is maintained in SGNs during circuit assembly. A, A diagrammatic view of the cochlea. SGNs (green) extend projections radially through the mesenchyme and toward hair cells (purple) in the organ of Corti. Insets show the cochlea (lll bodies to form radial bundles. Type II projections are indicated by asterisks. $\mathbf{E}-\mathbf{G}$, Immunostaining shows expression of Gata3 S a whole-mount of a PO cochlea (G). Gata3 protein is also detected in the cochlear duct (cd) at all stages, including hair cell and supporting cell nuclei in the organ of $\mathrm{Corti}(\mathrm{OC})$ at $\mathrm{PO}$. sg, Spiral ganglion. Scale bar: $\boldsymbol{B}-\boldsymbol{D}, 50 \mu \mathrm{m}$.

number of caspase-positive SGNs was observed between control and Gata3 ${ }^{C K O}$ mutants at E14.5, a dramatic increase in the number of caspase-positive SGNs was seen in Gata3 ${ }^{C K O}$ mutants at E15.5 (Fig. 3E-G), consistent with the decrease in cell density at E16.5 (Fig. 3B). Hence, Gata3 also appears to be necessary for survival of SGNs.

\section{Gata3 mutant SGNs are specified as auditory neurons and have grossly normal central projections}

Because Gata3 was deleted after initial fate specification events, we expected Gata ${ }^{C K O}$ mutant SGNs to be properly specified as auditory neurons. Indeed, mutant ganglia expressed two previously defined auditory markers, NetrinG1 and Chordin-like1 (Lu et al., 2011) (Fig. 4A-C). Similarly, X-gal staining of Gata3 ${ }^{C K O}$ 

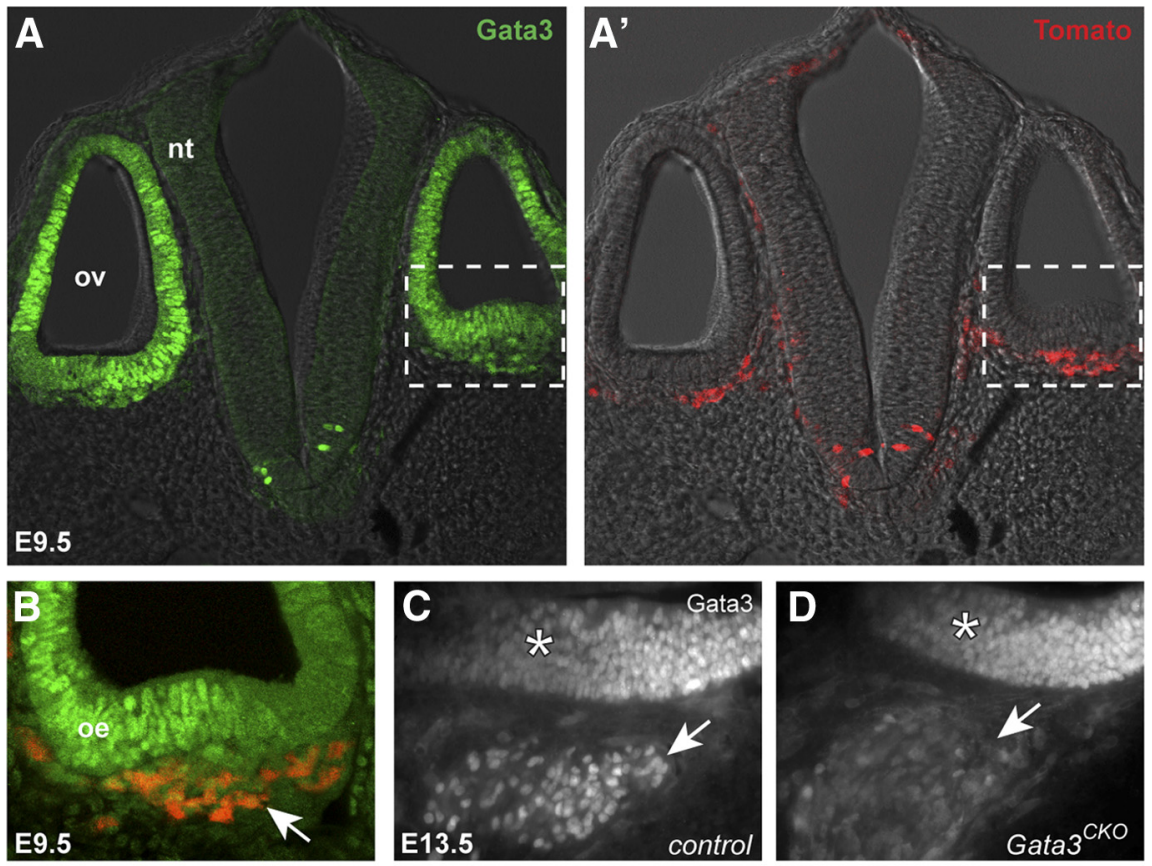

E

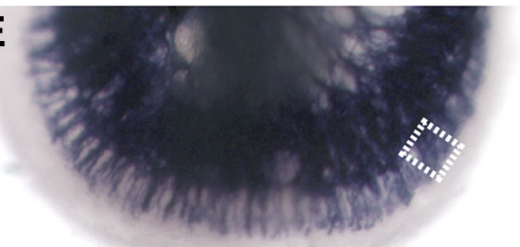

E15.5

control
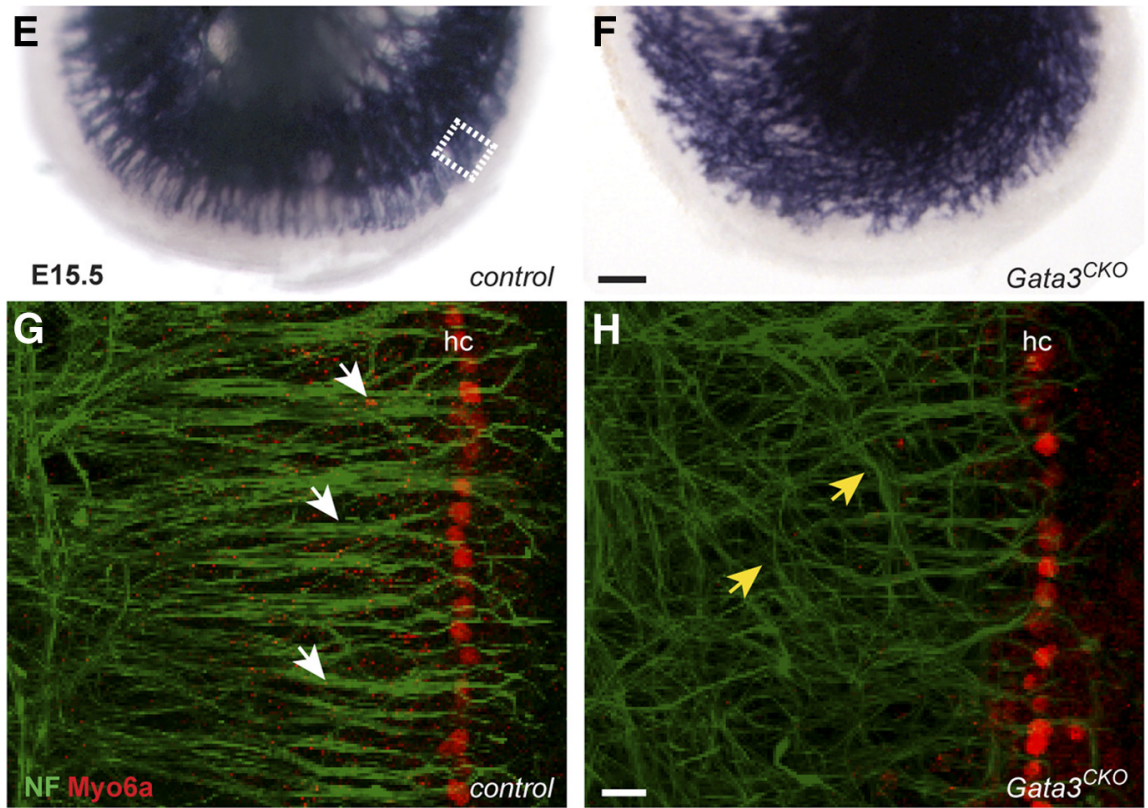

Figure 2. Gata 3 is essential for normal wiring of the cochlea. $A$, A transverse section through an E9.5 Bhlhb5-Cre;tdTomato embryo immunostained for Gata3 (green), which is broadly expressed in the otic vesicle (ov) and in delaminated neurons. Dorsal is up. nt, Neural tube. $\boldsymbol{A}^{\prime}$, Cre recombination drives Tomato expression (red) in delaminated neurons but not in the otic vesicle (ov). Boxes outline the region shown in $\boldsymbol{B}$. $\boldsymbol{B}$, A merged image of Tomato and Gata3 expression in the ventral otic vesicle showing Tomato in delaminated Gata3-positive neurons (arrow) but not in Gata3-positive cells still within the otic epithelium (oe). C, D, Gata3 immunostaining of transverse sections through E13.5 control $(\boldsymbol{C})$ and Gata ${ }^{\mathrm{CKO}}(\boldsymbol{D})$ cochleae. In Gata3 ${ }^{\mathrm{CKO} O}$ mutants, Gata3 protein is severely reduced in SGNs (arrow) but is maintained in the cochlear duct (asterisk), in which hair cells and support cells will develop. $\boldsymbol{E}, \boldsymbol{F}$, Whole-mount PLAP-stained cochleae from E15.5 Bhlhb5-Cre;Gata $3^{f / /} ; \mathrm{Z} / \mathrm{AP}(\boldsymbol{E})$ and Bhlhb5-Cre; Gata ${ }^{\mathrm{fl} /-} ; \mathrm{Z} / \mathrm{AP}(\boldsymbol{F})$ embryos. SGN processes align in orderly radial bundles in the control $(\boldsymbol{E})$ but form a disordered meshwork in the $\mathrm{Gata}^{3 \mathrm{CKO}}(\boldsymbol{F}) . \mathbf{G}, \boldsymbol{H}$, E15.5 whole-mount cochleae from control $(\boldsymbol{G})$ and $\mathrm{Gata}^{\mathrm{CKO}}(\boldsymbol{H})$ embryos were double stained for Neurofilament (NF) (green) to label neuronal processes and Myo6 (red) to label inner hair cells (hc). Field of view is similar to boxed region in $\boldsymbol{E}$. Processes extend radially and bundle in control animals (white arrows, $\boldsymbol{G}$ ). In mutants, the processes often travel tangentially (yellow arrows, $\boldsymbol{H}$ ) but still extend toward the hair cells. Some processes extend past the inner hair cells toward outer hair cells in both genotypes. Scale bars: (in $\boldsymbol{F}), \boldsymbol{E}, \boldsymbol{F}, 100 \mu \mathrm{m}$; (in $\boldsymbol{H}) \boldsymbol{G}, \boldsymbol{H}, 10 \mu \mathrm{m}$.

mice carrying the Gata3 tau-lacZ reporter allele showed maintained activity of the Gata3 locus, the earliest indicator of auditory fate (Fig. 4D-F). Moreover, Gata3 mutant axonal projections to the cochlear nucleus were grossly normal, with no obvious misprojections outside of the appropriate target area (Fig. $4 G, H$ ). In contrast to the obvious disruption of peripheral wiring, SGN central projections maintained their overall tonotopic organization within both the nerve and the cochlear nucleus, with no major intermingling observed. Thus, several signifiers for SGN auditory fate specification are preserved, and Gata3 appears to primarily regulate development of the peripheral SGN projections.

\section{Gata3 regulates intrinsic SGN neurite outgrowth}

To determine whether Gata3 regulates the progression of auditory circuit assembly events, we examined the transition from cell specification to differentiation. Because the earliest overt sign of SGN differentiation is the outgrowth of projections toward the cochlear duct, we consider this event to mark the onset of differentiation. At E12.5, control SGN projections were just beginning to extend beyond the border of the ganglion (Fig. $5 A, A^{\prime}$ ). In contrast, Gata3 ${ }^{C K O}$ SGN projections had already extended farther at this stage (Fig. $\left.5 C, C^{\prime}\right)$, occupying approximately twice as much area in mutants $(n=2)$ (Fig. $\left.5 D, D^{\prime}\right)$ compared with controls $(n=2)$ (Fig. $5 B, B^{\prime}$ ). Two days later, mutant neurites were noticeably closer to the edge of the cochlea (Fig. 5E,F). These observations suggest that the roles of Gata3 evolve over the course of development from regulating production of SGNs to controlling the onset of their differentiation.

To test whether this precocious outgrowth was attributable to changes in intrinsic properties of Gata3 mutant neurons, we developed an in vitro assay for SGN neurite outgrowth. Indeed, Gata $3^{C K O}$ mutant spiral ganglia (Fig. $5 H$ ) exhibited notably increased neurite outgrowth relative to controls (Fig. $5 G$ ), with a higher NOI in mutants $(2.29 \pm 1.5, n=18)$ compared with littermate controls $(1.18 \pm 1.22$, Crenegative Gata $\left.^{f l /+}, n=19\right)(p=0.004$ by KS test) (Fig. 5I). Heterozygous ganglia showed an intermediate effect, with average indices of $1.7 \pm 0.68\left(\right.$ Gata $\left.^{f l-}, n=12\right)$ and $1.75 \pm$ 1.38 (Bhlhb5-Cre;Gata $\left.3^{f l /+}, n=30\right)$. This is consistent with the fact that Gata3 is haploinsufficient in humans and mice (Van Esch et al., 2000; van Looij et al., 2005) and suggests that Gata3 also has dose-dependent effects in SGNs. However, cochlear innervation was normal in Gata3 heterozygotes (Fig. 2E and data not shown). Hence, Gata3 appears to control an intrinsic program of neurite outgrowth timing in SGNs that is independent of its effects on cell specification and axon guidance. 

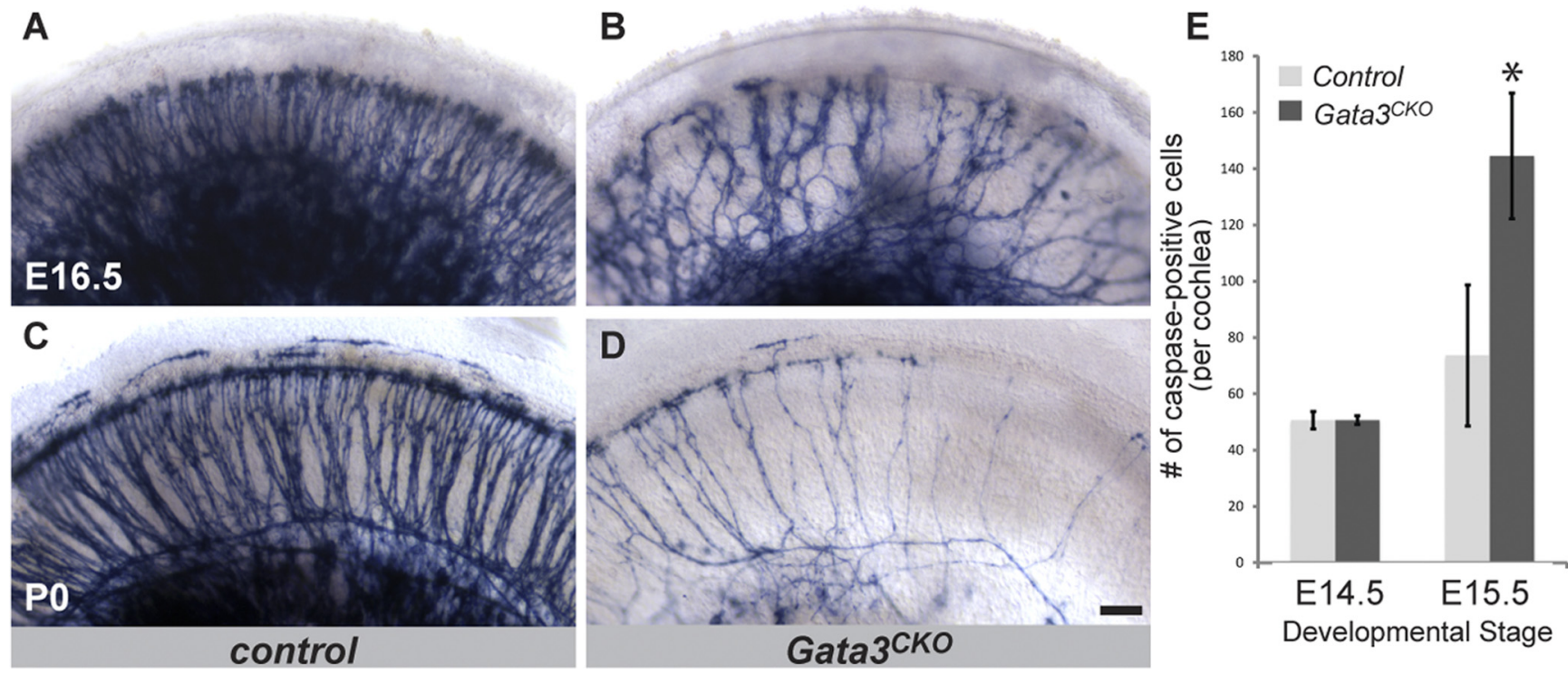

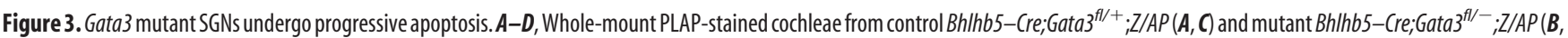
D) embryos. By E16.5, SGN projections reach their target area in the cochlear epithelium $(\boldsymbol{A})$. In Gata3 ${ }^{C K O}$ mutants, a reduction in the number of projections is observed $(\boldsymbol{B})$. By P0, a dramatic loss of SGNs is evident in Gata $^{C K O}$ mutants (D) compared with controls (C).E, Quantification of apoptosis by caspase antibody staining. At E14.5, no difference in the average number of caspase-positive SGNs is observed between control ( $51 \pm 3.1$ cells, $n=3)$ and Gata ${ }^{C K O}$ mutant $(51 \pm 1.5$ cells,$n=3)$ embryos. However, by E15.5, a significant increase in the number of caspase-positive SGNs is observed in Gata3 ${ }^{C K O}$ mutants ( $145 \pm 22.3$ cells, $\left.n=4\right)$ compared with controls $(74 \pm 25$ cells, $n=5)\left({ }^{*} p=0.003\right.$ by Student's $t$ test).

\section{Gata3 mutant SGN projections follow} aberrant trajectories

During development, the next step after SGN specification and the initiation of neurite outgrowth is guidance of neurites toward hair cells. However, technical limitations have to date made it impossible to visualize the SGN processes interacting with their presynaptic partners. To capture how these events unfold in real time in vivo, we established a novel method that combines genetic labeling and live imaging to visualize SGN outgrowth in control and mutant embryonic cochleae (Fig. 6), starting at E14.5 and continuing for 12-24 h. At the start of imaging, control neurons had extended short processes from the edge of the ganglion cell body region toward the developing hair cells (Fig. 6A,B). Over the next few hours, the processes lengthened and organized into radial bundles extending to the sensory epithelium. In contrast, outgrowth in mutant cochleae was clearly altered (Fig. 6C). Consistent with previous observations, the mutant SGN neurites had progressed farther toward the sensory epithelium by the start of the experiment compared with controls. Whereas control neurites showed rapid elongation toward the sensory epithelium, the mutant neurite wave front made little progress over the course of the experiment. However, individual processes continued to grow behind the wave front.

Next, we examined the path that the neurites take en route to the sensory epithelium. We focused on an intermediate region $\sim 50 \mu \mathrm{m}$ away from the cell bodies and $\sim 50 \mu \mathrm{m}$ from the sensory epithelium (Fig. $6 B, C$, brackets), allowing us to disambiguate
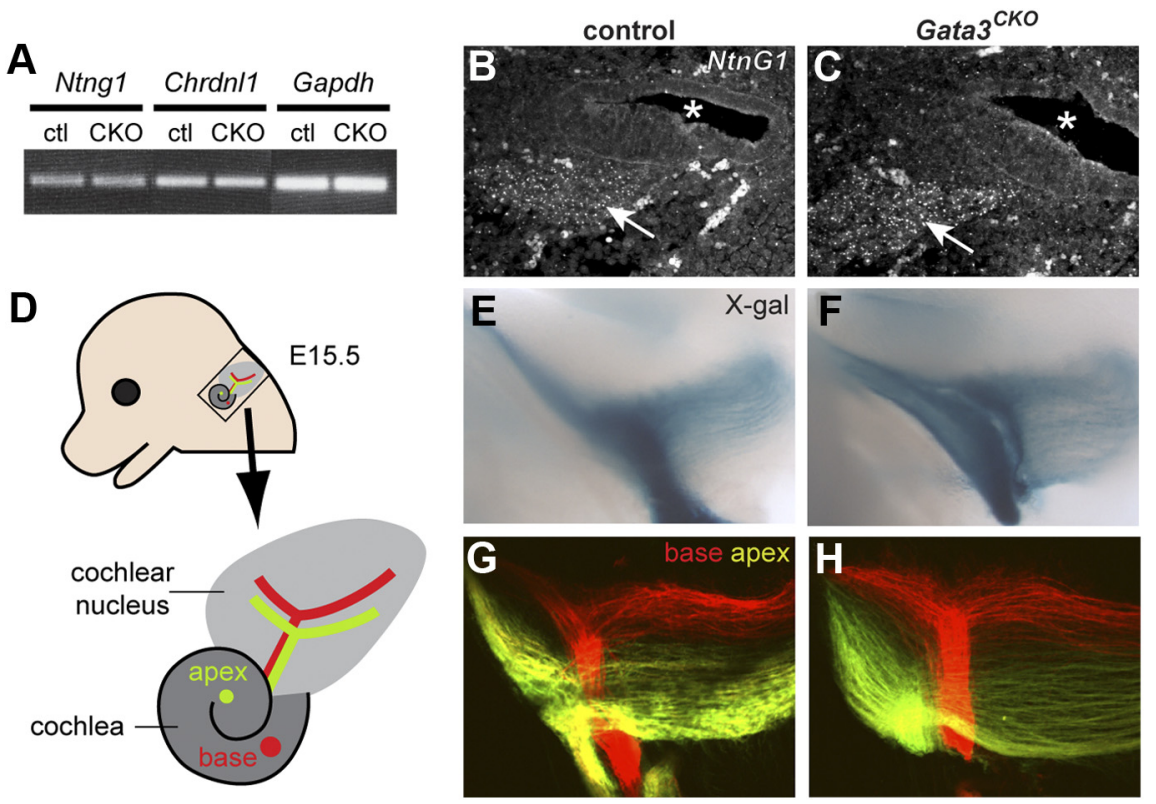

Figure 4. Gata3 mutant SGNs preserve salient features of the auditory fate. RT-PCR of microdissected E13.5 spiral ganglia $(\boldsymbol{A})$ and fluorescent in situ hybridization of E15.5 tissue ( $\boldsymbol{B}, \boldsymbol{C}$ ) confirm expression of the auditory markers NetrinG1 (NtnG1) and Chordinlike1 (Chrdn/1) in control (B) and Gata3 ${ }^{C K O}(\boldsymbol{C})$ animals. ctl, Control. Arrows point to SG; asterisks indicate cochlear duct. $\boldsymbol{D}$, Schematic view of the cochlea and its connections to the auditory brainstem. Projections from the base (red) terminate dorsal to the projections from the apex (green). $\boldsymbol{E}-\boldsymbol{H}$, Lateral views of X-gal-stained $(\boldsymbol{E}, \boldsymbol{F})$ and dye-labeled $(\boldsymbol{G}, \boldsymbol{H})$ projections in E15.5 hindbrains of control $(\boldsymbol{E}, \boldsymbol{G})$ and $G a t a 3^{C K O}(\boldsymbol{F}, \boldsymbol{H})$ animals. The Gata3 locus remains active $(\boldsymbol{F})$, and there is no obvious loss of tonotopy in mutants $(\boldsymbol{H})$ compared with controls $(\boldsymbol{G})$. No projections outside of auditory targets were noted using either approach. effects on outgrowth from effects on guidance, because both control and mutant neurites were growing through analogous regions, albeit at different times. Individual neurites $(>14$ processes per animal in four controls and four mutants) were tracked for $8-10 \mathrm{~h}$, marking the location of their leading edge every 10-24 min (Fig. 6D,E). In controls, neurites grew steadily and radially toward the sensory epithelium. In contrast, mutant neu- 

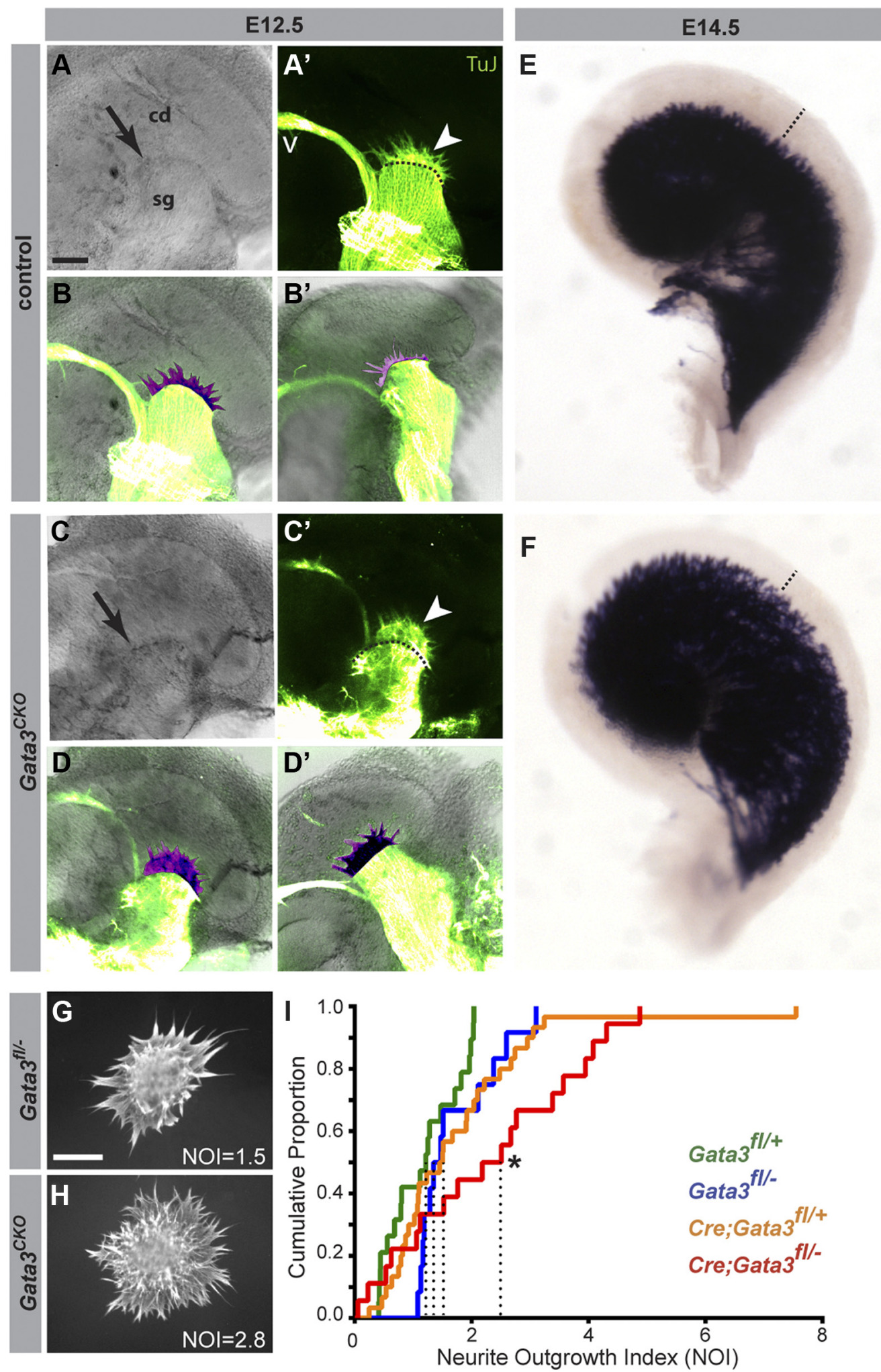

Figure 5. Loss of Gata3 causes precocious and exuberant neurite outgrowth. $\boldsymbol{A}, \boldsymbol{C}$, Bright-field images $(\boldsymbol{A}, \boldsymbol{C})$ and TuJ immunostaining $\left(\boldsymbol{A}^{\prime}, \boldsymbol{C}^{\prime}\right)$ of whole cochleae from E12.5 control $(\boldsymbol{A})$ and $G$ ata $3^{\mathrm{CKO}}$ (C) embryos. TuJ-positive neurites (arrowheads) have extended farther from the edge of the spiral ganglion (sg) and toward the cochlear duct (cd) in mutants than in controls. $v$, Vestibular projection. $\boldsymbol{B}, \boldsymbol{D}$, Merged images of bright-field and TuJ-immunostained E12.5 cochleae from two control $\left(\boldsymbol{B}, \boldsymbol{B}^{\prime}\right)$ and two mutant $\left(\boldsymbol{D}_{\mathbf{D}}, \mathbf{D}^{\prime}\right)$ animals. The TuJ-positive neurite area beyond the edge of the SG (dashed lines, $\left.\boldsymbol{A}^{\prime}, \boldsymbol{C}^{\prime}\right)$ is colored in magenta. Total neurite area is $5231 \mu \mathrm{m}^{2}(\boldsymbol{B})$ and $5008 \mu \mathrm{m}^{2}\left(\boldsymbol{B}^{\prime}\right)$ in heterozygotes and $10,756 \mu \mathrm{m}^{2}(\boldsymbol{D})$ and $11,755 \mu \mathrm{m}^{2}\left(\boldsymbol{D}^{\prime}\right)$ in mutants. $\boldsymbol{E}, \boldsymbol{F}$, E14.5 control $(\boldsymbol{E})$ and $\operatorname{Gata}^{\mathrm{CKO} O}(\boldsymbol{F})$ PLAP-stained cochleae. The distance between the neurites and the edge of the cochlea (dotted line) is shorter in mutants than in controls. $\mathbf{G}, \boldsymbol{H}$, TuJ immunostained E12.5 control $(\boldsymbol{G})$ and mutant $(\boldsymbol{H}) \mathrm{SG}$ grown for four days in vitro. The NOI, calculated by normalizing the area of TuJ-positive neurites to the area of the cell-body-containing region of the explant, is shown for each explant. I, A cumulative distribution plot of neurite outgrowth in wild-type (Gata $\left.{ }^{f /+}, n=19\right)$, heterozygous (Gata $3^{f / /}, n=12$ and Bhlhb5-Cre; Gata3 $\left.{ }^{f / /+}, n=30\right)$ and mutant $(B h / h b 5-C r e$; $\left.\mathrm{Gata}^{f / /}{ }^{-}, n=18\right)$ explants. The $y$-axis reports the proportion of explants that have NOIs less than or equal to the value on the $x$-axis. The mutant curve is significantly shifted to the right $\left({ }^{*} p=0.004\right.$ by KS test). Median values for each genotype are indicated by dashed lines. Scale bar: (in $\boldsymbol{A}) \boldsymbol{A}-\boldsymbol{D}, 100 \mu \mathrm{m}$; (in $\mathbf{G}) \mathbf{G}, \boldsymbol{H}, 500 \mu \mathrm{m}$. 

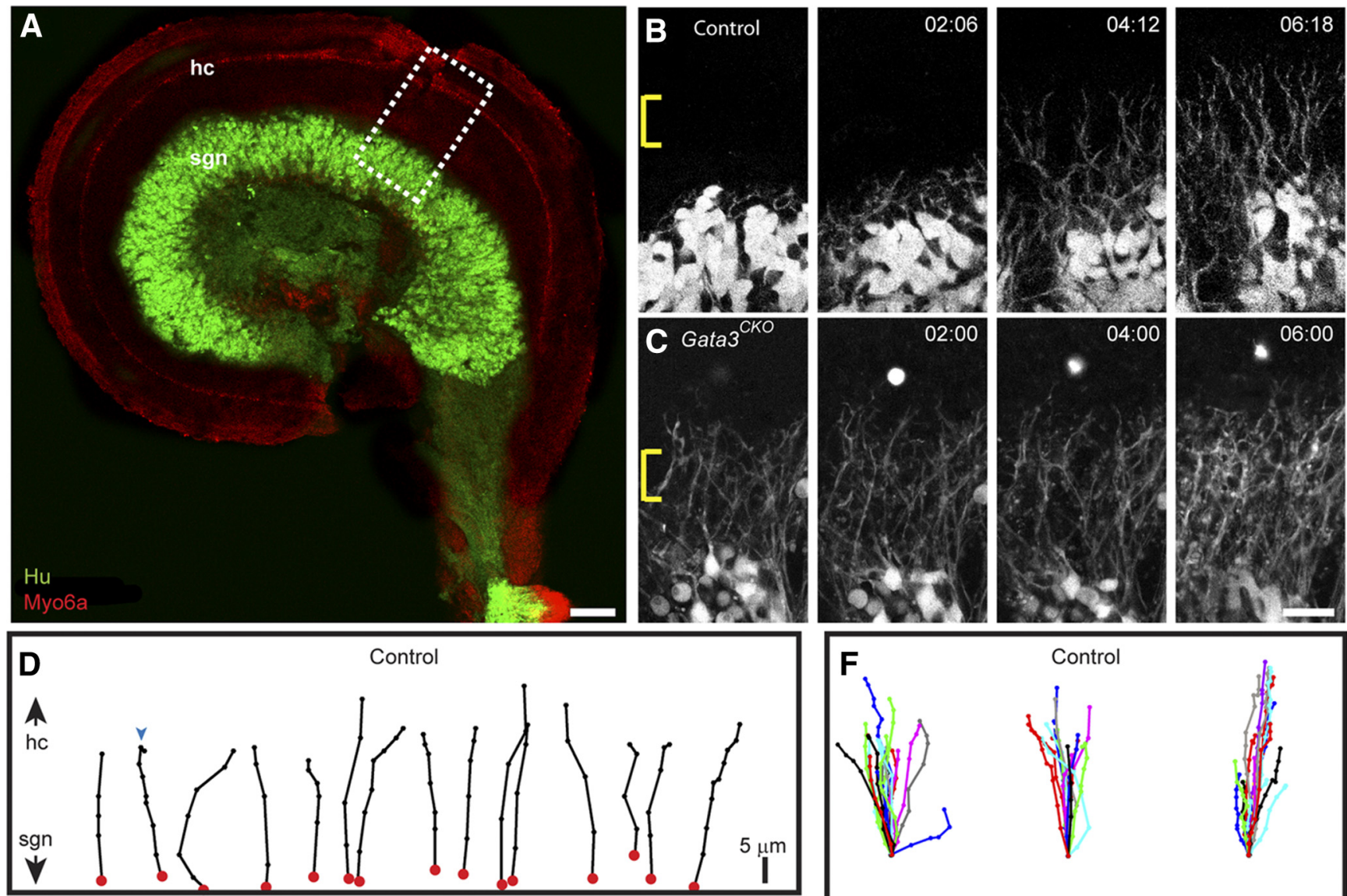

E Gata3 $^{\text {CKO }}$
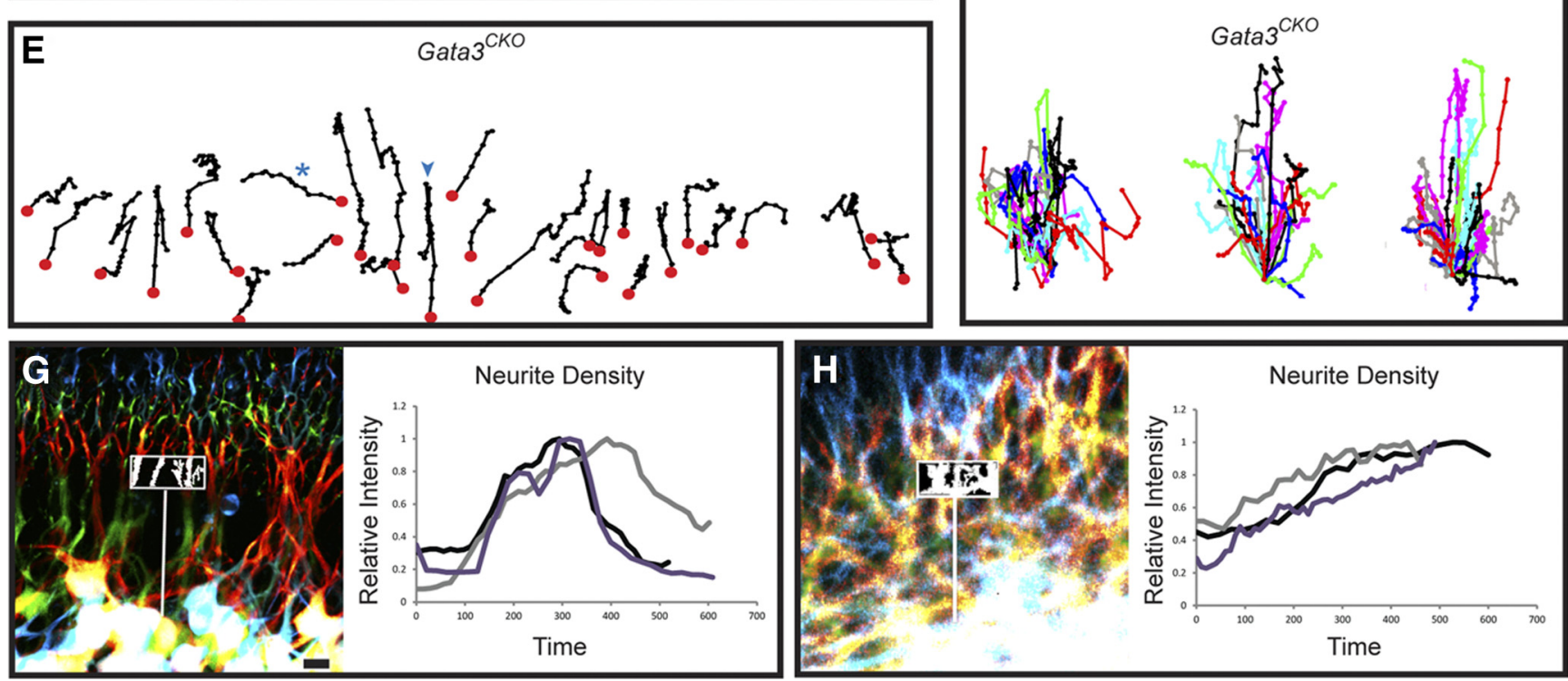

Figure 6. Live imaging shows that Gata3 mutant neurites follow aberrant paths in the cochlea. $A$, Whole-mount E14.5 cochlea immunostained for the neuronal cell body marker Hu (green) and the hair cell marker Myo6a (red). At this stage, SGNs (sgn) are $\sim 125-150 \mu \mathrm{m}$ away from the hair cells (hc). Scale bar, $100 \mu \mathrm{m}$. B, C, Frames from movies of GFP-labeled neurites in E14.5 control (B) and $\mathrm{Gata}^{\mathrm{C} K O}(\boldsymbol{C})$ cochleae. Box in $\boldsymbol{A}$ indicates imaging region. Time of image is hours:minutes. Scale bar, $50 \mu \mathrm{m}$. $\boldsymbol{D}-\boldsymbol{F}$, SGN neurite trajectories in representative control (D) and mutant $(\boldsymbol{E})$ cochleae, in the 50- $\mu \mathrm{m}$-long region bracketed in $\boldsymbol{B}$ and $\boldsymbol{C}$, starting $\sim 50 \mu \mathrm{m}$ away from the edge of the $S G$. The red dot shows the start position, and black dots show subsequent positions after each interval. Mutant neurites frequently double back (arrowhead, $\boldsymbol{E}$ ), whereas control neurites reverse only rarely and for short distances (arrowhead, $\boldsymbol{D}$ ). Mutant neurites travel tangentially (asterisk) more frequently than in controls. $\boldsymbol{F}$, Trajectories from control $(n=3)$ and $\operatorname{Gata}^{\mathrm{CKO}}(n=3)$ animals plotted with the start positions superimposed. Control projections are noticeably more radial than those in mutants. $\mathbf{G}, \boldsymbol{H}$, Neurite density was measured by quantifying the fluorescence intensity in a $30 \times 15 \mu \mathrm{m}$ box, as shown, for controls $(\boldsymbol{G})$ and mutants $(\boldsymbol{H})$ over $\sim 8-10 \mathrm{~h}$. Black, gray, and purple lines in the graphs illustrate data from three animals for each genotype. Images were taken of the tissue at $t=24 \mathrm{~h}$. Scale bar, $10 \mu \mathrm{m}$. See Notes.

rites did not progress as far between intervals and frequently moved in a non-radial direction (Fig. $6 E$, asterisk), with $45 \%$ of mutant neurites ( $n=143$ total neurites) showing obvious tangential trajectories compared with only $8 \%$ in controls $(n=94$ total neurites) (Fig. $6 F$ ). We also frequently observed processes that doubled back (Fig. $6 E$, arrowhead), making $4.1 \pm 3.28$ reversals per trajectory compared with $0.5 \pm 1.03$ in controls (Fig. $6 D$, arrowhead) $(p<0.0001$ based on negative binomial GEE esti- 
mates). The net effect of these abnormal guidance events was that mutant neurites remained within the same region of the cochlea but continued to grow and overlap each other. Because neurites normally became neatly bundled after an initial period of outgrowth, neurite density within a single region peaked and then declined in controls (Fig. 6G). However, in mutants, the neurites wandered locally and failed to form bundles, so neurite density steadily increased over time (Fig. $6 H$ ), eventually creating the reticulated array of processes typical of the Gata3 phenotype. Hence, although both the in vitro explants and in situ imaging revealed early outgrowth of Gata3 mutant neurites, the in situ observations demonstrate that subsequent guidance through the cochlea was also abnormal.

\section{Gata3 coordinates programs of gene expression associated with differentiation and identity}

Together with previous findings, our observations suggest that Gata3 plays an important role in the production of SGNs and subsequently regulates critical circuit assembly events, such as the timing and trajectory of SGN neurite outgrowth. To elucidate how Gata3 mediates these diverse effects at the transcriptional level, we performed a microarray comparison of control and mutant SGNs at E13.5, when SGNs are undergoing active differentiation and axon guidance.

We found that 444 genes exhibited significantly altered expression in Gata3 mutants, with 290 genes showing decreased expression and 154 genes showing increased expression (see Notes). Gene ontology analysis showed that the downregulated genes were predominantly involved in processes such as transcription, mRNA processing, and neuronal differentiation, events we previously associated with early SGN and VGN development (Lu et al., 2011). In contrast, upregulated genes were associated with functions in more mature SGNs and VGNs, such as cell adhesion, extracellular matrix, protein transport, ion channel activity, and synaptic transmission. Hence, the overall program of gene expression in Gata ${ }^{C K O}$ neurons is shifted toward a more mature state. This suggests that the premature extension of Gata3 mutant SGN processes may reflect an overall acceleration of differentiation rather than simple activation of a program for neurite outgrowth.

To assess whether the overall timing of SGN differentiation is affected in Gata3 mutants, it is necessary to have a global view of how gene expression changes in normal SGNs during development. Previously, we cataloged gene expression in SGNs and VGNs as they transition between circuit assembly events (Lu et al., 2011). We were therefore able to categorize all 444 target genes based on the normal spatiotemporal expression profile of each gene. This analysis confirmed that the accelerated differentiation of Gata3 mutant neurons is accompanied by an overall shift in the timing of gene expression. For instance, a large proportion of genes downregulated in Gata3 ${ }^{\mathrm{CKO}}$ mutant SGNs $(56 \%)$ are normally expressed in SGNs at early stages of development and then decline during later stages (Fig. 7A). Conversely, $33 \%$ of the upregulated genes are those that are expressed in more mature neurons in wild-type animals (Fig. 7B). Strikingly, many of these timing-related genes are expressed in both SGNs and VGNs. For instance, $79 \%$ of the early downregulated genes are normally expressed in both types of inner ear neurons. Similarly, half of the mid/late upregulated genes are normally present at similar levels in both populations. Intriguingly, SG-specific gene expression (i.e., "SG-early" and "SG-mid/late") shifted in parallel with the overall acceleration of neuronal differentiation programs. Thus, Gata3 appears to control SGN differentiation by coordinating the timing of both generic and cell-type-specific programs of gene expression.

If the function of Gata3 is to ensure a smooth transition from specification to differentiation, we reasoned that certain features of cell identity may be abnormal, despite the overall preservation of SGN fate. Indeed, close examination of the overall programs of gene expression normally associated with SGNs or VGNs revealed a partial shift in SGN identity. For instance, a small number of genes that are normally enriched in VGNs were aberrantly upregulated in Gata $3^{\mathrm{CKO}}$ mutant SGNs (Fig. 7B). Conversely, a small proportion of downregulated genes were "SG markers" (4\%) (Fig. 7A). Importantly, SGNs clearly did not undergo a wholesale shift in identity, because they still expressed the majority of SG markers correctly (92\%), including Ntng1, and sent their projections to the correct targets (Figs. 2, 4). Moreover, the vast majority of VG marker (97\%) genes remained unchanged in Gata $^{C K O}$ mutant SGNs. Thus, after initial specification events have occurred, maintained expression of Gata3 is required to suppress expression of vestibular genes and to maintain an SGNspecific program of development as these neurons begin to undergo auditory-specific aspects of differentiation.

Additional changes in gene expression suggest that Gata3 is also required for negotiating the transition to the terminal differentiation stage of development. Indeed, despite the overall acceleration of differentiation, a small number of SG-specific genes that normally peak during mid/late stages ("SG mid/late") were downregulated in Gata ${ }^{C K O}$ mutant SGNs, suggesting a failure to initiate the execution of SG-specific differentiation events. This category included the transcription factor Mafb, which is normally upregulated in SGNs after early specification events (Lu et al., 2011). Intriguingly, Mafb and other Maf factors are wellestablished regulators of terminal differentiation (Yang and Cvekl, 2007). Whether Mafb plays such a role in SGNs is not known, because Mafb mutant mice die at birth (Blanchi et al., 2003; Moriguchi et al., 2006).

To confirm these microarray trends, we defined a set of genes representative of each category ("identity," "early," and "late"), based on their normal spatiotemporal expression profiles (Fig. $7 C, D)$. qPCR of microdissected E13.5 SG from control and mutant littermates demonstrated downregulation of genes expressed in both SG and VG at early stages, concomitant with upregulation of genes normally expressed at later stages (Fig. 7E). These changes were accompanied by enhanced expression of vestibular genes and loss of the late auditory-specific gene Mafb. Thus, Gata3 acts via multiple gene expression cassettes to coordinate the timing of differentiation with the maintenance of SG fate, thereby ensuring formation of the precisely arrayed connections that underlie the perception of sound.

\section{Discussion}

Here, we demonstrate that a single transcription factor, Gata3, orchestrates multiple facets of SGN development to generate the exquisitely wired circuits of the cochlea. In addition to being required for the initial specification of SGNs, continued Gata3 activity controls the timing of SGN neurite outgrowth, as well as their trajectories within the cochlea. This is also evident at the molecular level, in which we found changes in both generic developmental timing and auditory-specific programs of gene expression. Moreover, maintained Gata3 expression is necessary for repression of vestibular genes in SGNs, underscoring the ongoing nature of cell fate determination. Thus, Gata3 ensures that SGNs are both properly specified and wired for the sense of hear- 
ing. These studies establish Gata3 as the first auditory-specific regulator of SGN development.

\section{Gata3 links cell identity and the progress of differentiation}

Gata3 is well known as a master regulator of cell fate in other cell types, such as the Th2 lineage in the immune system (Ho et al., 2009). Whereas previous studies suggested an analogous role for Gata3 in the inner ear (Karis et al., 2001; LawokoKerali et al., 2004; Lilleväli et al., 2006; Duncan et al., 2011; Haugas et al., 2012), we additionally found that, when Gata3 was deleted from SGNs after delamination, mutant neurons were able to send processes to auditory-specific targets and appropriately expressed most identity genes. Nevertheless, identity was partially dysregulated at the molecular level. This suggests that neuronal identity is more complex than an initial specification event and must be actively maintained at later stages. At the same time, Gata3 also regulates the pace of neuronal differentiation, including both generic programs of neurite outgrowth and celltype-specific aspects of differentiation. Thus, Gata3 appears to link cell identity and neuronal differentiation programs, which may prevent SGNs from losing their identity while they undergo dramatic morphological and molecular changes. Indeed, maintenance of cell identity through cellular transitions may be a general role of Gata factors, because Gatal has been shown recently to maintain the transcriptional identity of blood cells as they progress through mitosis, in a process known as "mitotic bookmarking" (Kadauke et al., 2012).

It should be noted that few examples of accelerated neuronal differentiation have been described to date and have been mostly limited to studies in Caenorhabditis elegans (Olsson-Carter and Slack, 2010, 2011). In part, this may be because the systems-level expression analysis we performed here requires a large wild-type dataset that spans multiple time points and allows the developmental status of neurons to be correlated with specific changes in gene expression. Nonetheless, the importance of developmental timing in neural circuit assembly should not be underestimated; indeed, in the cochlea, SGN differentiation must be coordinated with the development of many surrounding cell types, including hair cells, which do not begin to differentiate until E14.5 (Woods et al., 2004; Lee et al., 2006). Interestingly, Gata3 is also expressed in the

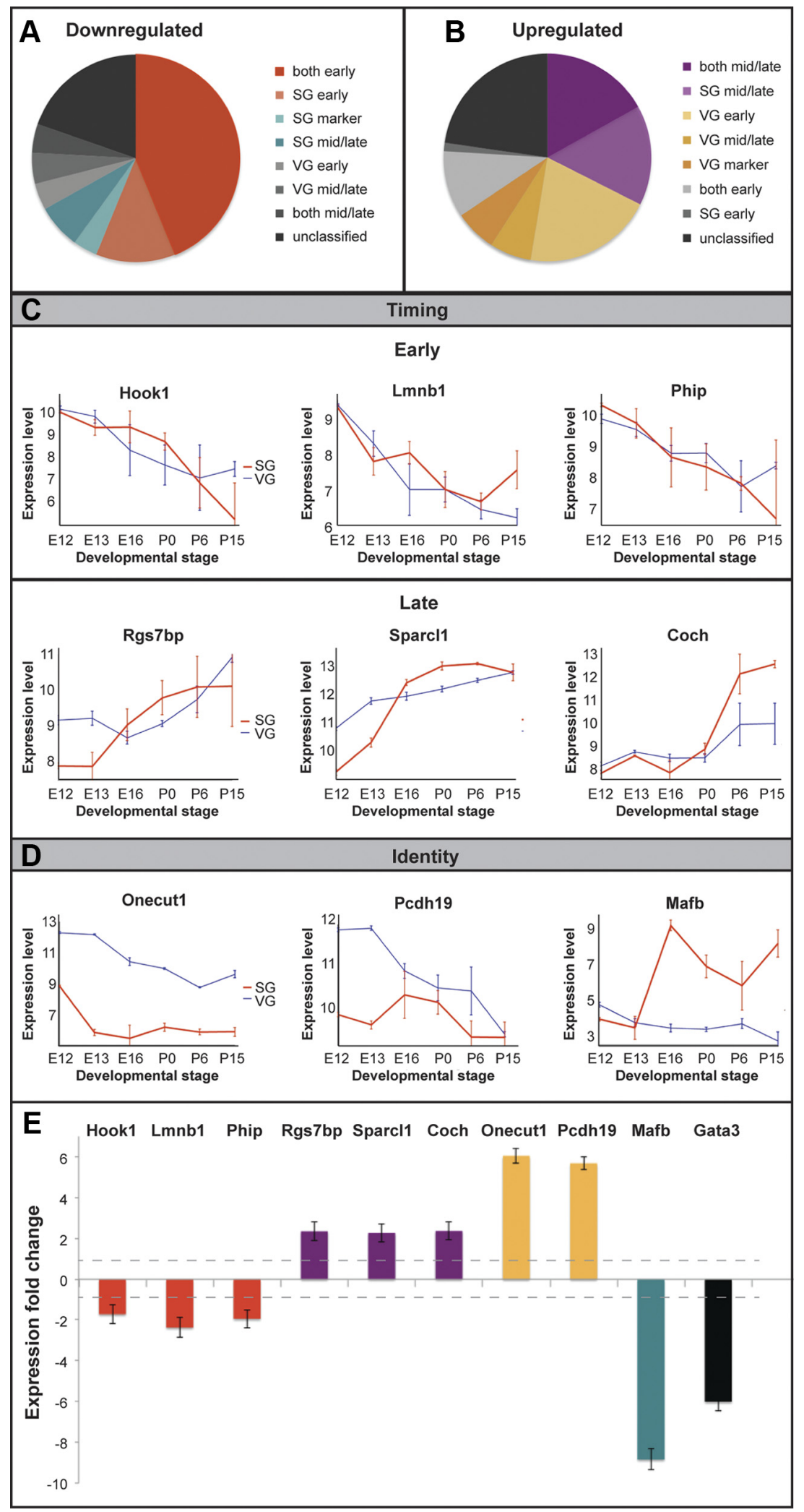

Figure 7. Genome-wide and qPCR analysis reveals that identity and developmental timing are misregulated in Gata3 ${ }^{\text {CKO }}$ SGNs. $\boldsymbol{A}, \boldsymbol{B}$, Categorization of downregulated $(\boldsymbol{A})$ and upregulated $(\boldsymbol{B})$ target genes based on their normal spatiotemporal expression profiles. $\boldsymbol{C}$, Normal expression profiles of genes expressed in both SGNs and VGNs that are enriched either at early (Hook1, Lmnb1, and Phip) or late stages (Rgs7bp, Spard1, and Coch) of developmental timing. D, Normal spatiotemporal expression profiles of genes that reflect the vestibular (Pcdh19 and Onecut) or auditory (Mafb) identity. $\boldsymbol{E}$, Fold change in expression of identity and timing genes in Gata $3^{\text {CKO }}$ versus wild-type SGNs, as assessed by qPCR. Positive values indicate upregulation in mutant SGNS, whereas negative values indicate downregulation. Note that Gata3 expression is approximately sixfold reduced in Gata $3^{\mathrm{CKO}}$ versus wild-type SGNs, whereas Mafb is $\sim 8.8$-fold reduced. Area between the dotted lines indicates no change in expression. Error bars show the SD of $\Delta C(t)$. 


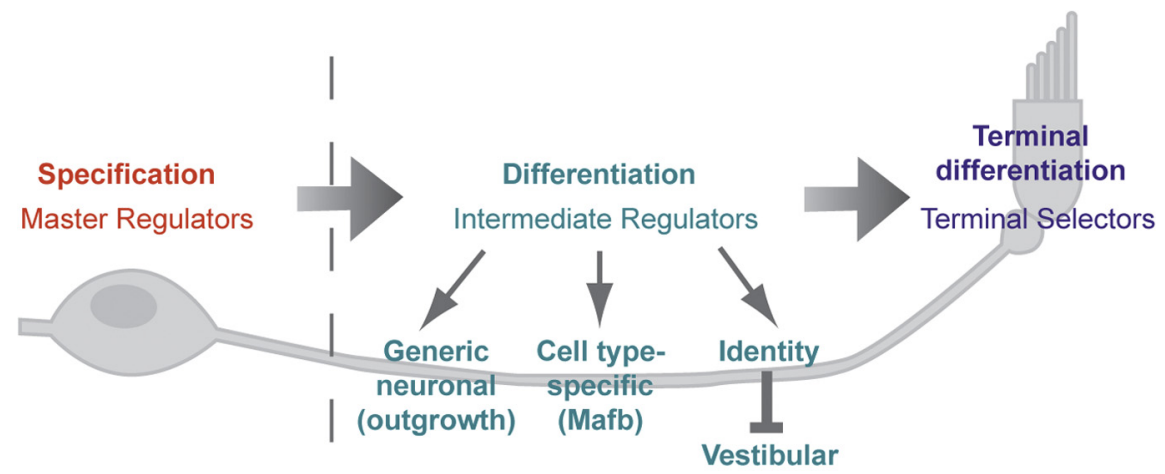

Developmental time

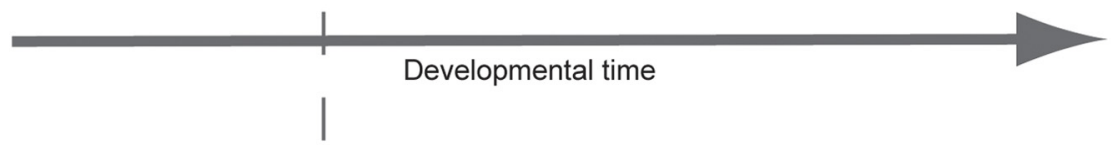

Differentiate

No SGNs

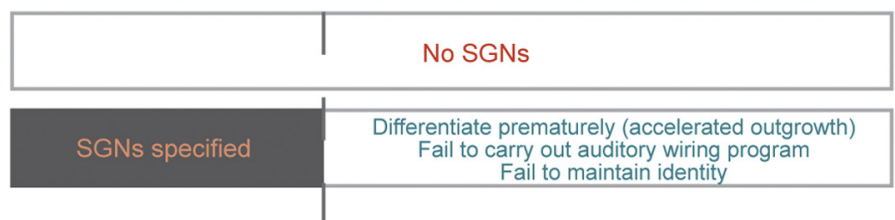

Figure 8. Model for transcriptional regulation throughout neuronal development. Initial specification of neurons is controlled by master regulators. Intermediate regulators guide neurons through the subsequent differentiation steps, coordinating the timing of generic neurite outgrowth programs, promoting the expression of cell-type-specific differentiation genes that may control axon guidance and targeting and repressing expression of genes normally found in other neuron types (e.g., repression of vestibular genes in SGNs). Finally, terminal selectors activate expression of terminal differentiation genes that endow neurons with their specific mature functions. Gata3 expression is shown in the bars below, with black indicating normal expression and white indicating loss of Gata3. In the wild-type cochlea, SGN specification and differentiation are normal. In Gata3 constitutive mutants, lack of early Gata3 expression in SGN precursors results in loss of SGNs. In Gata ${ }^{\mathrm{CKO}}$ mutants, in which early Gata3 expression in SGN precursors is maintained, $\mathrm{SGNs}$ are specified. However, subsequent loss of Gata3 after delamination results in premature differentiation of SGNs, which is manifested in accelerated neurite outgrowth and shifts in the timing of gene expression, such that early neuronal genes are downregulated and mid/late neuronal genes are upregulated. In addition, Gata $3^{\mathrm{CKO}}$ mutant SGNs fail to perform the proper auditory wiring program, with aberrant neurite pathfinding in the cochlea. Finally, Gata ${ }^{\mathrm{CKO}}$ mutant SGNs fail to fully maintain their identity and instead express some vestibular neuron genes.

organ of Corti and may be involved in hair cell differentiation (Rivolta and Holley, 1998; Haugas et al., 2012), suggesting that the differentiation of SGNs and their targets may share some regulatory mechanisms in common.

\section{Gata3 and cochlear wiring}

One of the most severe consequences of attenuated Gata3 is the loss of the highly stereotyped and intricate pattern of cochlear wiring. The live imaging studies suggest this is attributable to impaired pathfinding abilities, evidenced by the high incidence of neurites reversing their growth or following non-radial paths. At present, little is known about the cues that might be present in the surrounding tissue (Fekete and Campero, 2007). Among known guidance pathways, neurotrophins have been shown to play a prominent role (Yang et al., 2011). However, we did not observe any changes in Trk receptor expression by either microarray or Western blot (data not shown). Similarly, although FGF signaling can promote in vitro neurite extension in SGNs (Zhou et al., 1996; Hossain and Morest, 2000), our microarray data did not reveal significant changes in FGF receptor or Akt expression in Gata3 mutant SGNs. Indeed, no single axon guidance receptor emerged from the microarray studies as a strong candidate effector of the Gata3 phenotype, with only subtle changes in levels rather than profound loss or gain of expression of known guidance mole-
Wild-type

Gata3 $^{-/-}$

Gata3 ${ }^{C K O}$

cules. Although important new studies have shown that EphA4 in the mesenchyme is essential for formation of radial bundles (Coate et al., 2012), the EphA4 mutant phenotype primarily reflects defasciculation and is much milder than the Gata3 mutant phenotype. Hence, unlike transcription factors that mediate their effects through clearly defined target genes, Gata3 may act instead through networks of genes. Some of these effects may be performed by downstream transcription factors, such as Mafb, that may have simpler and more restricted functions.

\section{Gata3 as a multifunctional regulator of SGN development}

Together, our data suggest a model for how transcriptional networks specify, maintain, and execute neuronal cell fates to form the precisely wired circuits that underlie neural function (Fig. 8). It is well established that the initial specification of neurons depends on master regulator genes that often act in combination. We propose that a class of "intermediate regulators" acts subsequently to guide neurons through an extended period of differentiation, during which cell fates are consolidated and appropriate connections are formed. Finally, once identities are consolidated and connections are formed, terminal selectors activate the expression of terminal differentiation genes so that the neurons can acquire their specific mature functions (Hobert, 2011). In this model, intermediate regulators act through multiple parallel subroutines to control both generic and cell-typespecific programs of development, as well as the overall timing of developmental transitions. This includes initiation of neurite outgrowth after specification, as well as the progression toward a terminally differentiated state. Notably, the same transcription factor may be involved in more than one step in this process, because Gata3 appears to be both a master regulator and an intermediate regulator in SGN development. Consistent with this evolving role, Gata3 is predicted to control distinct sets of target genes in different times and places. In support of this idea, we did not observe any significant change in expression of $F G F 10$, which is a confirmed target gene for Gata3 during earlier stages of inner ear development (Lilleväli et al., 2006; Economou et al., 2013). In addition, just as master regulators often function in combination to specify cell fates, multiple intermediate regulators likely control circuit assembly events, because we did not see significant defects in central SGN axons. Determining whether Gata3 may also play a role in terminal differentiation will require new Cre mouse lines permitting later deletion in SGNs.

Our observation that Gata3 mutant SGNs undergo increased cell death at E15.5, resulting in massive loss of neurons by $\mathrm{P} 0$, is intriguing, but at present we do not know whether this reflects a direct role for Gata3 during later stages of auditory circuit assembly. One possibility is that the miswiring or timing defects lead to missed neurotropic survival cues. Alternatively, the increased cell 
death could be attributable to an independent role for Gata3 in survival, consistent with its effects in sympathetic neurons (Tsarovina et al., 2010). Additional studies will be required to distinguish between these possibilities.

Our findings have important implications for ongoing efforts to develop a stem-cell-based approach to reverse deafness. Recently, human embryonic stem cells steered to develop as auditory progenitors were able to restore some auditory sensitivity in a gerbil model (Chen et al., 2012). Together with work aimed at regenerating hair cells, this represents a significant advance. However, although the presence of SGN-like neurons may be sufficient to improve the detection of sound, restoration of complex tasks, such as understanding spoken language, will require that stem-cell-derived SGNs perfectly recapitulate their natural properties. Our results reveal that more sophisticated analyses of SGN identity are needed, because Gata3 mutant neurons misexpressed a small number of vestibular-specific genes even while preserving many aspects of auditory identity. In addition, SGNs generated in vitro will also need to be capable of establishing their normal intricate and complex pattern of connectivity. The identification of Gata3 as a critical regulator of cochlear wiring suggests that dissection of the Gata3 transcriptional network in SGNs will pave the way for converting stem cells into bona fide SGNs that form functional auditory circuits.

\section{Notes}

Supplemental material for this article is available at http://goodrich.med. harvard.edu/resources/resources.htm. A complete list of Gata3 target genes as well as the original movies are available for download in the Resources section of our laboratory website. This material has not been peer reviewed.

\section{References}

Abraira VE, Del Rio T, Tucker AF, Slonimsky J, Keirnes HL, Goodrich LV (2008) Cross-repressive interactions between Lrig3 and netrin 1 shape the architecture of the inner ear. Development 135:4091-4099. CrossRef Medline

Alsina B, Abell ó G, Ulloa E, Henrique D, Pujades C, Giraldez F (2004) FGF signaling is required for determination of otic neuroblasts in the chick embryo. Dev Biol 267:119-134. CrossRef Medline

Appler JM, Goodrich LV (2011) Connecting the ear to the brain: molecular mechanisms of auditory circuit assembly. Prog Neurobiol 93:488-508. CrossRef Medline

Bielefeld EC, Tanaka C, Chen GD, Henderson D (2010) Age-related hearing loss: is it a preventable condition? Hear Res 264:98-107. CrossRef Medline

Blanchi B, Kelly LM, Viemari JC, Lafon I, Burnet H, Bévengut M, Tillmanns S, Daniel L, Graf T, Hilaire G, Sieweke MH (2003) MafB deficiency causes defective respiratory rhythmogenesis and fatal central apnea at birth. Nat Neurosci 6:1091-1100. CrossRef Medline

Carney PR, Silver J (1983) Studies on cell migration and axon guidance in the developing distal auditory system of the mouse. J Comp Neurol 215: 359-369. CrossRef Medline

Chen W, Jongkamonwiwat N, Abbas L, Eshtan SJ, Johnson SL, Kuhn S, Milo M, Thurlow JK, Andrews PW, Marcotti W, Moore HD, Rivolta MN (2012) Restoration of auditory evoked responses by human ES-cellderived otic progenitors. Nature 490:278-282. CrossRef Medline

Coate TM, Raft S, Zhao X, Ryan AK, Crenshaw EB 3rd, Kelley MW (2012) Otic mesenchyme cells regulate spiral ganglion axon fasciculation through a Pou3f4/EphA4 signaling pathway. Neuron 73:49-63. CrossRef Medline

David-Fung ES, Yui MA, Morales M, Wang H, Taghon T, Diamond RA, Rothenberg EV (2006) Progression of regulatory gene expression states in fetal and adult pro-T-cell development. Immunol Rev 209:212-236. CrossRef Medline

Duncan JS, Lim KC, Engel JD, Fritzsch B (2011) Limited inner ear morphogenesis and neurosensory development are possible in the absence of GATA3. Int J Dev Biol 55:297-303. CrossRef Medline
Economou A, Datta P, Georgiadis V, Cadot S, Frenz D, Maconochie M (2013) Gata3 directly regulates early inner ear expression of Fgf10. Dev Biol 374:210-222. CrossRef Medline

Fairman CL, Clagett-Dame M, Lennon VA, Epstein ML (1995) Appearance of neurons in the developing chick gut. Dev Dyn 204:192-201. CrossRef Medline

Fekete DM, Campero AM (2007) Axon guidance in the inner ear. Int J Dev Biol 51:549-556. CrossRef Medline

Friedman LM, Dror AA, Avraham KB (2007) Mouse models to study inner ear development and hereditary hearing loss. Int J Dev Biol 51:609-631. CrossRef Medline

Hama H, Kurokawa H, Kawano H, Ando R, Shimogori T, Noda H, Fukami K, Sakaue-Sawano A, Miyawaki A (2011) Scale: a chemical approach for fluorescence imaging and reconstruction of transparent mouse brain. Nat Neurosci 14:1481-1488. CrossRef Medline

Haugas M, Lilleväli K, Salminen M (2012) Defects in sensory organ morphogenesis and generation of cochlear hair cells in Gata3-deficient mouse embryos. Hear Res 283:151-161. CrossRef Medline

Ho IC, Tai TS, Pai SY (2009) GATA3 and the T-cell lineage: essential functions before and after T-helper-2-cell differentiation. Nat Rev Immunol 9:125-135. CrossRef Medline

Hobert O (2011) Regulation of terminal differentiation programs in the nervous system. Annu Rev Cell Dev Biol 27:681-696. CrossRef Medline

Hossain WA, Morest DK (2000) Fibroblast growth factors (FGF-1, FGF-2) promote migration and neurite growth of mouse cochlear ganglion cells in vitro: immunohistochemistry and antibody perturbation. J Neurosci Res 62:40-55. CrossRef Medline

Kadauke S, Udugama MI, Pawlicki JM, Achtman JC, Jain DP, Cheng Y, Hardison RC, Blobel GA (2012) Tissue-specific mitotic bookmarking by hematopoietic transcription factor GATA1. Cell 150:725-737. CrossRef Medline

Karis A, Pata I, van Doorninck JH, Grosveld F, de Zeeuw CI, de Caprona D, Fritzsch B (2001) Transcription factor GATA-3 alters pathway selection of olivocochlear neurons and affects morphogenesis of the ear. J Comp Neurol 429:615-630. CrossRef Medline

Konings A, Van Laer L, Van Camp G (2009) Genetic studies on noiseinduced hearing loss: a review. Ear Hear 30:151-159. CrossRef Medline

Koundakjian EJ, Appler JL, Goodrich LV (2007) Auditory neurons make stereotyped wiring decisions before maturation of their targets. J Neurosci 27:14078-14088. CrossRef Medline

Lawoko-Kerali G, Rivolta MN, Lawlor P, Cacciabue-Rivolta DI, LangtonHewer C, van Doorninck JH, Holley MC (2004) GATA3 and NeuroD distinguish auditory and vestibular neurons during development of the mammalian inner ear. Mech Dev 121:287-299. CrossRef Medline

Lee YS, Liu F, Segil N (2006) A morphogenetic wave of p27Kip1 transcription directs cell cycle exit during organ of Corti development. Development 133:2817-2826. CrossRef Medline

Lilleväli K, Matilainen T, Karis A, Salminen M (2004) Partially overlapping expression of Gata2 and Gata3 during inner ear development. Dev Dyn 231:775-781. CrossRef Medline

Lilleväli K, Haugas M, Matilainen T, Pussinen C, Karis A, Salminen M (2006) Gata3 is required for early morphogenesis and Fgf10 expression during otic development. Mech Dev 123:415-429. CrossRef Medline

Lobe CG, Koop KE, Kreppner W, Lomeli H, Gertsenstein M, Nagy A (1999) Z/AP, a double reporter for cre-mediated recombination. Dev Biol 208: 281-292. CrossRef Medline

Lu CC, Appler JM, Houseman EA, Goodrich LV (2011) Developmental profiling of spiral ganglion neurons reveals insights into auditory circuit assembly. J Neurosci 31:10903-10918. CrossRef Medline

Ma Q, Chen Z, del Barco Barrantes I, de la Pompa JL, Anderson DJ (1998) neurogenin 1 is essential for the determination of neuronal precursors for proximal cranial sensory ganglia. Neuron 20:469-482. CrossRef Medline

Matei V, Pauley S, Kaing S, Rowitch D, Beisel KW, Morris K, Feng F, Jones K, Lee J, Fritzsch B (2005) Smaller inner ear sensory epithelia in Neurog 1 null mice are related to earlier hair cell cycle exit. Dev Dyn 234:633-650. CrossRef Medline

Moriguchi T, Hamada M, Morito N, Terunuma T, Hasegawa K, Zhang C, Yokomizo T, Esaki R, Kuroda E, Yoh K, Kudo T, Nagata M, Greaves DR, Engel JD, Yamamoto M, Takahashi S (2006) MafB is essential for renal development and F4/80 expression in macrophages. Mol Cell Biol 26: 5715-5727. CrossRef Medline

Novak A, Guo C, Yang W, Nagy A, Lobe CG (2000) Z/EG, a double reporter 
mouse line that expresses enhanced green fluorescent protein upon Cremediated excision. Genesis 28:147-155. CrossRef Medline

Okano T, Kelley MW (2012) Stem cell therapy for the inner ear: recent advances and future directions. Trends Amplif 16:4-18. CrossRef Medline

Olsson-Carter K, Slack FJ (2010) A developmental timing switch promotes axon outgrowth independent of known guidance receptors. PLoS Genet 6:e1001054. CrossRef Medline

Olsson-Carter K, Slack FJ (2011) The POU transcription factor UNC-86 controls the timing and ventral guidance of Caenorhabditis elegans axon growth. Dev Dyn 240:1815-1825. CrossRef Medline

Pai SY, Truitt ML, Ting CN, Leiden JM, Glimcher LH, Ho IC (2003) Critical roles for transcription factor GATA-3 in thymocyte development. Immunity 19:863-875. CrossRef Medline

Quinoñes HI, Savage TK, Battiste J, Johnson JE (2010) Neurogenin 1 (Neurog1) expression in the ventral neural tube is mediated by a distinct enhancer and preferentially marks ventral interneuron lineages. Dev Biol 340:283-292. CrossRef Medline

Rivolta MN, Holley MC (1998) GATA3 is downregulated during hair cell differentiation in the mouse cochlea. J Neurocytol 27:637-647. CrossRef Medline

Ross SE, Mardinly AR, McCord AE, Zurawski J, Cohen S, Jung C, Hu L, Mok SI, Shah A, Savner EM, Tolias C, Corfas R, Chen S, Inquimbert P, Xu Y, McInnes RR, Rice FL, Corfas G, Ma Q, Woolf CJ, Greenberg ME (2010) Loss of inhibitory interneurons in the dorsal spinal cord and elevated itch in Bhlhb5 mutant mice. Neuron 65:886-898. CrossRef Medline

Tsarovina K, Reiff T, Stubbusch J, Kurek D, Grosveld FG, Parlato R, Schütz G, Rohrer H (2010) The Gata3 transcription factor is required for the survival of embryonic and adult sympathetic neurons. J Neurosci 30:10833-10843. CrossRef Medline

van Doorninck JH, van Der Wees J, Karis A, Goedknegt E, Engel JD, Coes- mans M, Rutteman M, Grosveld F, De Zeeuw CI (1999) GATA-3 is involved in the development of serotonergic neurons in the caudal raphe nuclei. J Neurosci 19:RC12(1-8). Medline

Van Esch H, Groenen P, Nesbit MA, Schuffenhauer S, Lichtner P, Vanderlinden G, Harding B, Beetz R, Bilous RW, Holdaway I, Shaw NJ, Fryns JP, Van de Ven W, Thakker RV, Devriendt K (2000) GATA3 haploinsufficiency causes human HDR syndrome. Nature 406:419-422. CrossRef Medline

van Looij MA, van der Burg H, van der Giessen RS, de Ruiter MM, van der Wees J, van Doorninck JH, De Zeeuw CI, van Zanten GA (2005) GATA3 haploinsufficiency causes a rapid deterioration of distortion product otoacoustic emissions (DPOAEs) in mice. Neurobiol Dis 20:890-897. CrossRef Medline

Woods C, Montcouquiol M, Kelley MW (2004) Math1 regulates development of the sensory epithelium in the mammalian cochlea. Nat Neurosci 7:1310-1318. CrossRef Medline

Yang T, Kersigo J, Jahan I, Pan N, Fritzsch B (2011) The molecular basis of making spiral ganglion neurons and connecting them to hair cells of the organ of Corti. Hear Res 278:21-33. CrossRef Medline

Yang Y, Cvekl A (2007) Large Maf transcription factors: cousins of AP-1 proteins and important regulators of cellular differentiation. Einstein J Biol Med 23:2-11. Medline

Zhou X, Hossain WA, Rutledge A, Baier C, Morest DK (1996) Basic fibroblast growth factor (FGF-2) affects development of acoustico-vestibular neurons in the chick embryo brain in vitro. Hear Res 101:187-207. CrossRef Medline

Zhu J, Min B, Hu-Li J, Watson CJ, Grinberg A, Wang Q, Killeen N, Urban JF Jr, Guo L, Paul WE (2004) Conditional deletion of Gata3 shows its essential function in $\mathrm{T}(\mathrm{H}) 1-\mathrm{T}(\mathrm{H}) 2$ responses. Nat Immunol 5:11571165. CrossRef Medline 